Canadian

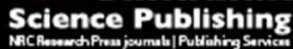

Canadian Geotechnical Journal Revue canadienne de géotechnique

\title{
Behavior of Soil Heave Inside of Stiffened Caissons Installing in Clay
}

\begin{tabular}{|r|l|}
\hline Journal: & Canadian Geotechnical Journal \\
\hline Manuscript ID & cgj-2016-0667.R1 \\
\hline Date Submitted by the Author: & 27-Apr-2017 \\
\hline Complete List of Authors: & $\begin{array}{l}\text { Zhao, Zhifeng; Nanjing Forestry University, School of Civil Engineering } \\
\text { Zhou, Mi; South China University of Technology, School of Civil and } \\
\text { Transportation Engineering; State Key Laboratory of Subtropical Building } \\
\text { Science; The University of Western Australia, School of Civil, } \\
\text { Environmental and Mining Engineering } \\
\text { Hu, Yuxia; University of Western Australia, } \\
\text { Hossain, Muhammad; The University of Western Australia, Centre for } \\
\text { Offshore Foundation Systems }\end{array}$ \\
\hline Is the invited manuscript for \\
consideration in a Special \\
Issue? :
\end{tabular}




\section{Behavior of Soil Heave Inside of Stiffened Caissons Installing in Clay}

\section{Zhifeng Zhao', Mi Zhou ${ }^{2}$, Yuxia Hu ${ }^{3}$ and Muhammad Shazzad Hossain ${ }^{4}$}

${ }^{1}$ Research Associate (PhD), School of Civil Engineering, Nanjing Forestry University, 159 Longpan Road, Nanjing, Jiangsu Province, China, Tel: +86 25 85427763, Fax: +86 25 85427763, Email: zzf0911@163.com

${ }^{2}$ Corresponding Author, Research Associate (PhD), School of Civil and Transportation Engineering; State Key Laboratory of Subtropical Building Science, South China University of Technology, 381 Wushan Road, Guangzhou 510640 China, Tel: +8620 87111029, Fax: +8620 87111029, Email: zhoumi@scut.edu.cn

Former Research Associate, School of Civil, Environmental and Mining Engineering, The University of Western Australia, Email: zhoumi@scut.edu.cn

${ }^{3}$ Professor (PhD, MIEAust), School of Civil, Environmental and Mining Engineering, The University of Western Australia, 35 Stirling Highway, Crawley, WA 6009, Tel: +61 86488 8182, Fax: +61 86488 1018, Email: yuxia.hu@uwa.edu.au

${ }^{4}$ Senior Research Fellow (BEng, MEng, PhD, MIEAust), Centre for Offshore Foundation Systems (COFS), The University of Western Australia, 35 Stirling Highway, Crawley, WA 6009, Tel: +61 86488 7358, Fax: +61 86488 1044, Email: muhammad.hossain@uwa.edu.au 
Abstract: Length of suction caisson anchors increases to support increasing dimensions and weight of floating facilities. This necessitates employing horizontal ring stiffeners at intervals along the inner wall of the thin skirt of caissons to ensure structural integrity. The addition of these stiffeners has created significant uncertainties regarding the soil flow mechanisms, in particular the soil heave inside the caisson, which may reduce the caisson final penetration depth and influence the process of installation due to the need to avoid inside soil suction into the pumping equipment. This paper reports results of large deformation finite element (LDFE) analyses investigating the soil heave inside stiffened caissons during installation in non-homogeneous clay deposits, with the corresponding evolution of soil flow mechanisms and penetration resistance profiles reported in Zhou et al. (2016). The LDFE analyses have simulated continuous penetration of stiffened caissons from the seabed surface. A detailed parametric study has been undertaken, exploring the relevant range of soil strength non-homogeneity and normalized strength, stiffened caisson geometry, soil effective unit weight and caisson roughness. Of particular interest was the influence of stiffeners on soil heave and potential penetration refusal. The results have been validated against previously published centrifuge test data in terms of soil heave and penetration resistance profile, with good agreement obtained. It was shown that the soil normalized strength at the mudline and its nonhomogeneity; caisson diameter relative to the sum of skirt thickness and stiffener width; and caisson penetration depth have significant influence on the inner soil heave and its profile across the caisson radius. An expression, based on the LDFE results, was proposed to predict the maximum inner soil heave during installation of stiffened caissons in the field.

Key words: clays, caissons, stiffeners, soil heave, numerical modelling, offshore engineering. 


\section{Introduction}

\section{Stiffened Suction Caisson Anchors and inside Soil Heave}

Offshore developments moving beyond the immediate continental shelf into deeper waters (now approaching $3000 \mathrm{~m}$ depths) has been driven by the vibrant oil and gas industry and the world's ever increasing demands for energy. These deep water developments rely on floating facilities (e.g. floating production storage and offloading vessels, tension leg platforms, SPAR platforms, and emerging concepts such as floating liquefied natural gas (FLNG) facilities) moored to the seabed through mooring chains and anchoring systems, with suction caissons being identified as the most viable option (Iskander et al. 2002; Fu et al. 2014). Caissons are also used as foundations to support pipeline manifolds and end terminations, subsea structures, and riser towers. In the renewable energy industry, they are increasingly being considered for anchoring floating turbines.

Suction caissons are installed by pumping water from inside the caisson after it is allowed to penetrate under its self-weight (see Figure 1). Analyses are sometimes carried out using jacking installation process to simplify the problem, especially for caisson in clay, where a caisson is pushed in soil up to the full penetration depth (similar to driven pile).

To comply with the increasing size of the floating facilities to be anchored (e.g. the Prelude FLNG is $488 \mathrm{~m}$ long and $75 \mathrm{~m}$ wide), suction caissons are designed as longer and wider - currently up to $30 \mathrm{~m}$ long, with a length to diameter (aspect) ratio $L / D$ in the range 2 to 7 (Andersen et al. 2005; Randolph et al. 2011). As the thickness of the skirt $(t)$ is restricted to less than $50 \mathrm{~mm}$ to ensure installation viability, the longer caissons are required to include horizontal ring stiffeners at intervals along the inner 
wall of the thin skirt with local thickening of the wall in the vicinity of the padeye, with or without transverse struts, for structural integrity.

The addition of these stiffeners has created significant uncertainties regarding the soil flow mechanisms, in particular the inner soil heave with the risk of potential penetration refusal prior to reaching the designed installation depth (or achieving the designed capacity to sustain operational loadings). The pattern of soil flow at the caisson tip, and the proportion of the caisson wall that is accommodated by inward or outward displacement of the soil, has important consequences for quantifying (i) the external radial stress and excess pore pressure, and ultimately long-term external shaft friction following consolidation; (ii) the internal side friction and stiffener end bearing. The behaviour of the clay plug can also affect the maximum penetration depth of the caisson. This is more critical for stiffened caisson. If the plug remains fully or partially self-supporting above the horizontal stiffeners, the gaps formed between the stiffeners result in greater heave volume, and hence higher inner seabed elevation. This paper has specifically focused on the quantification of inner soil heave during installation of stiffened caissons.

Andersen et al. (2005) discussed predictions for four different hypothetical installation cases and six case histories carried out by four predictors using their normal design method. For the hypothetical cases, the predictors calculated different soil heave height inside caisson due to different assumptions in terms of the proportion of soil flow inside caisson, soil plug heave standing ability, and soil infilling in the gaps between the embedded stiffeners. For the case histories presented, comparison between the calculated and observed soil heave showed that soil infilling in the gaps between the embedded stiffeners dictated the soil heave height, with the assumption 
of no soil infilling in the gaps and fully filled gaps providing over and under predictions respectively.

\section{Measured Data for Soil Heave Inside Caisson}

Dendani and Colliat (2002), Erbrich and Hefer (2002) and Andersen et al. (2005) reported five case histories of stiffened caisson penetration in clay sediments. The recorded soil heave heights inside the caissons $\left(h_{\text {in }}\right)$ are listed in Table 1 . The Girassol and the Laminaria anchors were penetrated to refusal, and the plug heave was estimated as the difference between the anchor height and the penetration depth at the end of penetration. The Diana and the Marlin anchors were not penetrated to refusal. In the Nkossa case, echo sounders showed that the clay plug was generally 1 to $1.5 \mathrm{~m}$ lower than the outside clay surface at the end of penetration (Colliat et al. 1996). It was believed that this was because the anchor diameter $(4.5 \mathrm{~m})$ in the upper $7.5 \mathrm{~m}$ is larger than that $(4 \mathrm{~m})$ in the lower $4.8 \mathrm{~m}$, and as such, the clay plug would have filled the additional space and sunk down when that entered in the upper part. For all the centrifuge test cases, it is seen from Table 1 that penetration refusal occurred i.e. the final penetration depth is lower than the caisson skirt length.

Clukey (2005) also analyzed installation of four caissons, with $L / D=24 / 6.5=3.69$, in mostly normally consolidated clay at four different locations in the Gulf of Mexico. Direct evidence of soil heave has also been reported from field observations in the Gulf of Mexico at Na Kika (Newlin 2003) and Mad Dog (Schroeder et al. 2006). For these cases, interpretation of the observed heaves (either measured using a dipstick, or deduced from the maximum penetration) was complicated by internal stiffeners, variations in wall thickness along the caisson length, and the acknowledged limited accuracy of the field data. The results from the field measurements broadly, however, 
suggest that between $30 \%$ and $50 \%$ of the soil displaced by the caisson tip flowed inward during the self-weight plus suction penetration. In all the three cases the caissons had an external beveled tip, extending over $50 \sim 60 \%$ of the skirt tip, which may have encouraged outward flow of soil (Andersen et al. 2004).

\section{Previous Work}

Installation of suction caissons in clay has received significant attention through experimental, numerical and analytical work and field trials, mostly limited to penetration resistance (House and Randolph 2001; Randolph and House 2002; Zhou and Randolph 2006; Chen and Randolph 2007; Chen et al. 2009; Westgate et al. 2009; Vásquez et al. 2010; Gaudin et al. 2014; Zhou et al. 2016) among others. Except for Zhou and Randolph (2006), they have noticed no discernible difference in penetration resistance between jacked and suction-installed caissons. Significant proportion of soil flow was reported to occur inward into the caisson, with little outward flow.

Soil displacement during suction caisson installation has been reported by House and Randolph (2001), Andersen and Jostad (2004), Zhou and Randolph (2006), Chen and Randolph (2007), Westgate et al. (2009), Zhou et al. (2016). Andersen and Jostad (2002) suggested that for a flat-tipped caisson, the soil displaced by the caisson wall would divide approximately 50\% outside, and 50\% inside the caisson during jacking installation (or self-weight installation). However, once suction installation started, over about first one diameter penetration, there appeared a transition to $100 \%$ of the displaced soil being drawn inside the caisson.

Chen and Randolph (2007) and Chen et al. (2009) carried out centrifuge tests and large deformation finite element analyses on installation of a caisson with single stiffener in normally consolidated, lightly overconsolidated, and sensitive clays. From 
both measured and computed results, it is evident that the installation process, jacking or self-weight installation followed by suction, has significant impact on the flow pattern of soil at the flat caisson tip. For jacking installation the soil displaced by the caisson tip flowed mostly outward, whereas for self-weight plus suction installation, around $53 \%$ of the soil displaced by the caisson tip flowed inward. These degree of soil heave, and proportions of the embedded caisson wall volume accommodated by inward flow, lie towards the upper range of the just discussed field results. Note also that the model caisson had a much lower $D / t$ ratio of 60 compared to $\sim 120$ in the field cases, and unlike the field caissons had no external chamfer at the caisson tip.

From continuous penetration analyses (from a pre-embedment depth of $1 D$ ), Zhou and Randolph (2006) showed that for jacking installation, over the penetration range of 1 to 4 diameters, the proportion of embedded caisson wall volume accommodated by inward soil flow reduced from around $45 \%$ at the start to zero at about 4 diameters embedment. By contrast, for suction installation, the proportion of $65 \%$ stayed essentially constant through the depth of penetration.

House and Randolph (2001) examined centrifuge test data of a stiffened caissons installed in normally consolidated and overconsolidated clays. The soil heave height was verified by comparing the target and actual caisson penetration rate, confirming that the soil displaced by the penetrating skirts flowed entirely into the caisson.

From centrifuge tests, Westgate et al. (2009) measured inner soil heave mechanically inflight using an LVDT plunger and manually stopping the centrifuge after the completion of each test. For both stiffened and unstiffened caissons, the effect of installation method on the soil heave was shown to be minimal. The heave height was nearly double for the caisson with horizontal ring stiffeners compared to that for the 
unstiffened caisson with identical $D / t$ ratio and soil strength. An open cavity along the embedded stiffener was observed. In contrast to Andersen and Jostad (2002), Chen and Randolph (2007) and Chen et al. (2009), and Zhou and Randolph (2006), it was shown that, for a caisson with horizontal ring stiffeners, the measured inner soil heave for jacked installation and suction installation are very similar.

Through the results from large deformation finite element analyses on stiffened caissons installing in non-homogeneous clays, Zhou et al. (2016) identified two critical depths: (i) depth of rotational flow, $H_{\mathrm{r}}$ - the embedment depth of the bottom stiffener base at which soil starts to flow around the bottom stiffener, and subsequently, the bottom gap is filled gradually with further penetration of the caisson; (ii) limiting cavity depth, $H_{\mathrm{c}}-$ when the base of any stiffener other than the bottom one reaches this depth, soil infilling starts to occur into the gap above it. It was shown that these depths are functions of soil strength non-homogeneity and normalized strength $\left(s_{\mathrm{uHr} \text { (or Hc) }} / \gamma^{\prime} D\right.$, where $s_{\mathrm{uHr} \text { (or Hc) }}$ is the intact shear strength at the corresponding depth of $H_{\mathrm{r}}$ or $H_{\mathrm{c}}$ ) and relative diameter $D / t$. Expressions were proposed to estimate these depths according to

$$
\begin{aligned}
& \frac{H_{r}}{D}=\left(31.89 \frac{b}{D}+0.21\right)\left(\frac{s_{\mathrm{uH}}}{\gamma^{\prime} D}\right)^{6.73 \frac{b}{D}+0.577} \\
& \frac{H_{\mathrm{c}}}{D}=\left(13.88 \frac{b}{D}+1.02\right)\left(\frac{s_{\mathrm{uH}}}{\gamma^{\prime} D}\right)^{0.835}
\end{aligned}
$$

To avoid iterations, alternative expressions were proposed as

$$
\frac{H_{r}}{D}=\frac{C_{1} S^{C_{2}}}{1-\frac{k}{\gamma^{\prime}} C_{1} C_{2} S^{\left(C_{2}-1\right)}}
$$


$\left(C_{1}=31.89 b / D+0.21, C_{2}=6.73 b / D+0.577, S=s_{\mathrm{um}} / \gamma^{\prime} D\right)$

$\frac{H_{c}}{D}=\frac{C_{3} S^{C_{4}}}{1-\frac{k}{\gamma^{\prime}} C_{3} C_{4} S^{\left(C_{4}-1\right)}}$

where $C_{3}=13.88 b / D+1.02$ and $C_{4}=0.835$. However, the height of the soil heave was not reported.

\section{Objective of Present Study}

This paper reports the results from an extensive parametric investigation carried out through LDFE analysis in an attempt to provide a better estimate of the soil flowing inward and consequent soil heave associated with installation of stiffened caissons in non-homogeneous clays. The results lead to an expression to quantify the soil heave in the field. The corresponding penetration resistance profiles and evolution of soil flow mechanisms were reported in Zhou et al. (2016).

\section{Large Deformation FE Analysis}

This study has considered a stiffened caisson of diameter $D$ and length $L$ penetrating into a nonhomogeneous clay deposit as illustrated schematically in Figure 1, where the undrained shear strength of clay, $s_{\mathrm{u}}$, increases linearly with depth from a mudline intercept of $s_{\text {um }}$ with a gradient of $k$. The thickness of the caisson skirt is $t$. The ring stiffeners of width $b$, height $h$, and with edge to edge spacing $s$, are placed along the inner wall of the skirt, with the bottom stiffener positioned at a distance of $w$ from the skirt tip.

Large deformation finite element (LDFE) analyses were carried out simulating continuous penetration of a stiffened caisson from the surface of the non- 
homogeneous clay deposit. The simulation of penetration was achieved by specifying an automated downward displacement increment of the caisson (updated based on the current mesh condition) represented by a rigid skirt. The RITSS (Remeshing and Interpolation Technique with Small Strain; Hu and Randolph 1998) method, falling within arbitrary Lagrangian-Eulerian (ALE) finite element methods (Ghosh and Kikuchi 1991), was employed coupling with the finite element package AFENA (Carter and Balaam 1995). A typical mesh, with the caisson wall just entered the ground, is shown in Figure 2 featuring six-noded triangular elements (with three internal Gauss points). Caisson-soil interfaces were simulated using elastoplastic nodal joint elements (Herrmann 1978), and assigning strength of $\alpha s_{\mathrm{u}}$, where $\alpha$ is the interface friction coefficient and $s_{\mathrm{u}}$ is the local undrained shear strength of the soil.

A $10 D$ radius and $10 D$ depth axisymmetric soil domain was selected to preclude the influences from the boundaries. Total stress analyses of caissons undrained penetration were conducted modelling the soil as an elastoplastic material obeying a Tresca yield criterion, and prescribing Poisson's ratio $v=0.49$, friction and dilation angles $\phi=\psi=0$, and uniform stiffness ratio $E / s_{\mathrm{u}}=500$ (where $E$ is the Young's modulus) throughout the soil domain. The geostatic stress conditions were modelled using $K_{0}=1$.

The effects of strain softening and strain rate dependency of the undrained shear strength were not considered. These effects are resulted through comparison of the average shear strain experienced by soil particles as they traverse the flow mechanism associated with a caisson installation and the average shear strain rate in the flow mechanism with those induced during the assessment of the reference/design undrained shear strength. Randolph et al. (2007) illustrated that the average shear 
strain and the average shear strain rate in the flow mechanism for caisson quasi-static installation and triaxial tests, through which generally the design undrained shear strength is measured, are very similar, meaning that the effects of strain softening and strain rate dependency would be minimal. This justifies the results of this study noting that the interface friction coefficient $\alpha$ was considered, which provides good indication of these effects.

\section{Results and Discussion}

\section{Validation against previous work}

The results from LDFE analyses were validated against the computed inner soil heave ratio presented by Zhou and Randolph (2006) and the measured inner soil heave reported by Westgate et al. (2009). Zhou and Randolph (2006) performed an analyses on an unstiffened caisson of diameter $4 \mathrm{~m}$ penetrating (from a pre-embedment ratio of $1 D)$ in clay with undrained shear strength $s_{\mathrm{u}}=4+1.5 z \mathrm{kPa}\left(t=0.04 \mathrm{~m}, E / s_{\mathrm{u}}=500, \gamma^{\prime}\right.$ $=6.5 \mathrm{kN} / \mathrm{m}^{3}, K_{0}=0.8, \alpha=0.3$; Group I, Table 2). An LDFE/RITSS analysis was carried out using the same caisson geometry and soil input parameters. The inner heave volume ratio, $R_{\mathrm{vi}}$, is plotted in Figure $3 \mathrm{a}$ as a function of normalized caisson tip penetration depth, $d / D$ beneath the original soil surface. $R_{\mathrm{vi}}$ is calculated as the ratio of the inner heave volume to the soil volume replaced by the penetrated caisson wall. The profile by Zhou and Randolph (2006) is also included in the figure, showing reasonable agreement. The difference between the profiles may be due to the prescribed incremental displacements used in the analyses: in this study, the selection of incremental displacement is automated to optimise the calculation process based on the current mesh. This is potentially providing a better solution; however, in the 
analysis by Zhou and Randolph (2006), a fixed incremental displacement was prescribed. Over the caisson penetration from $1 D$ to $4 D$, the proportion of the volume of the caisson wall accommodate by inward soil flow showed an almost consistent decrease from the peak of $R_{\mathrm{vi}}=46 \%$ at $\mathrm{d} / \mathrm{D}=1.8$ down to zero (no further internal heave) at a depth of about $3.8 D$.

Validation was also carried out against the centrifuge test data reported by Westgate et al. (2009). A stiffened caisson of diameter $D=11.3 \mathrm{~m}$ was jacked in kaolin clay with $s_{\mathrm{u}}=10+2.8 z \mathrm{kPa}\left(k / \gamma^{\prime}=0.47, s_{\mathrm{um}} / \gamma^{\prime} D=0.15, S_{\mathrm{t}} \approx \sim 3, s / h=3.0, b / t=3.4, w / b=5.2\right)$. An analysis was conducted penetrating an identical stiffened caisson (assuming $\alpha=$ 0.2 ) from the seabed to a depth of $5 \mathrm{~m}$. A comparison of inner soil heave height, $h_{\mathrm{in}}$, is illustrated in Figure 3b. From this study, the soil heave close to the caisson is about four times of that at the center. The measured (averaged) soil heave profile is more levelled, which might be the effect of centrifuge ramping down before the measurement. During and after the centrifuge ramping down, swelling of the clay took place. The clay swelling was more free near the caisson center and more restrained near the skirt wall by the friction along the caisson (Westgate et al. 2009). However, the computed inner heave volumes are consistent with the centrifuge observation. A heaving line representing the volume of the displaced soil by the embedded stiffened caisson and open gaps above the embedded stiffener is also included in Figure 3b, confirming that the soil flow is directed mostly inner side of the caisson.

The validation of LDFE results in terms of penetration resistance profile against measured data can be found in Zhou et al. (2016) and hence is not repeated here. 


\section{Inner Soil Heaving: Effect of Various Factors}

Parametric analyses were performed varying (i) the normalized clay strength, $s_{\mathrm{um}} / \gamma^{\prime} D$, and corresponding soil non-homogeneity factor, $k / \gamma^{\prime}$; (ii) the ratio of the caisson diameter to the thickness of the skirt, $D /(b+t)$; (iii) the soil-skirt interface friction coefficient, $\alpha$; (iv) the soil effective unit weight, $\gamma^{\prime}$. The selected parameters are grouped in Table 2, with the focus of each group listed in the column of Notes.

\section{Evolution of Soil Flow Patterns}

Figure 4 displays typical soil failure mechanism for a stiffened caisson advancing in non-homogeneous clay deposits, with $s_{\mathrm{u}}=1+1 \mathrm{z} \mathrm{kPa} \mathrm{(Figure} \mathrm{4a)} \mathrm{and} 5+1 \mathrm{z} \mathrm{kPa}$ (Figure $4 \mathrm{~b})$, from the surface $(D=11.3 \mathrm{~m}, D / t=226, b=0.17 \mathrm{~m}, h / b=1.47$; in Group III, Table 2). The current penetration depth is $d / D=7 / 11.3=0.62$. From Figure 4 , it can be seen that the soil heaves more inside than outside of the caisson (i.e. $h_{\text {in }}>h_{\text {out }}$ ). This is due to the significant inward soil flow, the presence of stiffeners and the gap formed between the embedded stiffeners. Consequently, the disturbance of the soil outside the caisson is minimal during caisson installation, whilst the soil inside the caisson is sheared and remoulded, resulting in soil strength degradation. By comparing Figures $4 \mathrm{a}$ and $4 \mathrm{~b}$, it is apparent that normalised soil strength at the mudline, $s_{\mathrm{um}} / \gamma^{\prime} D$, and soil strength non-homogeneity, $k / \gamma^{\prime}$ dictate soil heaving and its pattern and the gap formation between the stiffeners. For the case with $s_{\mathrm{um}} / \gamma^{\prime} D=0.04$ and $k / \gamma^{\prime}=0.17$ (i.e. very soft deposit at the mudline, Figure 4a), the soil flows into the gaps between the embedded stiffeners more easily and early. Initial soil heaving adjacent to stiffeners caves in as cannot stand vertical, shifting the $h_{\text {in-max }}$ towards the centre of the caisson. Most of the gaps are therefore filled by soils. On the contrary, for the case with $s_{\mathrm{um}} / \gamma^{\prime} D=0.074$ and $k / \gamma^{\prime}=0.17$ (with higher strength at the mudline, 
Figure 4b), most of the gaps between the embedded stiffeners remain open and the heave inside the caisson is higher towards the caisson wall and lower towards the centre. A rotational flow mechanism appears around the bottom stiffener, and the $2^{\text {nd }}$ bottom stiffener scrapes the deformed soil wall into the gap. With the progress of caisson penetration, the gaps between the stiffeners are gradually filled, leading to the continuous change of the inner soil heave height, hence the heave volume ratio, $R_{\mathrm{vi}}$ (i.e. soil volume above the initial mudline inside the caisson). The identified factors influencing this process are discussed below in more detail.

Effect of Soil Strength $\left(s_{u m} / \gamma D, k / \gamma\right)$

To examine the effects of the soil normalized strength and its non-homogeneity, a group of analyses was performed varying $s_{\mathrm{um}}$ as $1,5,10 \mathrm{kPa}$; and $k$ as $1,2,3 \mathrm{kPa} / \mathrm{m}$ $(D=4 \mathrm{~m}, D / t=80, b=0.015 \mathrm{~m}, h / b=1.67$; Group III, Table 2). Figure 5a depicts the evolution of the inner soil heave across the caisson radius during caisson penetration in a relatively soft clay deposit $\left(s_{\mathrm{u}}=1+1 z \mathrm{kPa}, s_{\mathrm{um}} / \gamma^{\prime} D=0.04, k / \gamma^{\prime}=0.17\right)$. In this case, using Equations 1 and 2, the critical depths of rational flow and cavity formation can be estimated as $H_{\mathrm{r}} / D=0.15$ and $H_{\mathrm{c}} / D=0.18$, which correspond to the caisson tip penetration depths of $d / D=\left(H_{\mathrm{r}}+w\right) / D=0.65$ and $d / D=\left(H_{\mathrm{c}}+s+h+w\right) / D=1.24$, respectively. Initially soil heaves more towards the caisson wall (see the left figure of Figure $5 \mathrm{~b}$ ) as in the curve for $d / D=0.4$ in Figure 5a, leading to a convex heave profile with $h_{\text {in-max }}$ near the caisson wall. At this stage, the heaving rate $\left(R_{\mathrm{h}}=\Delta h_{\mathrm{in}-\max } / \Delta d\right)$ is very slow as only the skirt penetrates into the soil $(d / D<w / D=0.5)$. The rate increases sharply after the first/bottom stiffener penetrates into the soil $(d / D>w / D=$ $0.5)$.

For the case in Figure 5a, soil starts to flow into the bottom gap above the bottom 
stiffener, after the penetration depth reaching $d / D=0.65$ (corresponding to $H_{\mathrm{r}} / D$ ) for soil rotational flow, as well as caves in gradually (see the middle figure of Figure 5b). Therefore, for $d / D>0.65$, as penetration depth increases, the form of the heave profile across the caisson radius changes with the peak shifting towards the center of the caisson and the trough adjacent to the caisson wall (see the curves for $d / D>0.8$ ). As the soil backflow accelerates with infilling the gaps above the bottom $2^{\text {nd }}$ stiffener, the rate of increasing the magnitude of the peak heave $h_{\text {in-max }}$ reduces. For instance, with the caisson penetration increasing from $d=0.8 D$ to $1.2 D$, the heaving rate is $R_{\mathrm{h}}=$ $(0.35-0.21) /(1.2-0.8)=0.35$, which becomes nearly zero $\left(\right.$ as $R_{\mathrm{h}}=(0.59-0.58) /(2.4-2.0)$ $=0.025$ ) during caisson penetration from $d=2 D$ to $2.4 D$. After the heave reaching its peak at $d=2.4 D$, the heaving rate becomes negative (i.e. $R_{\mathrm{h}}<0$ for $d>2.4 D$; plugging). The soil heave inside the caisson nearly diminishes after the caisson penetration of $d=3.6 D$ (see the right figure of Figure $5 \mathrm{~b}$ ).

By contrast, where the stiffened caisson penetrates in a stiffer clay with higher $s_{\mathrm{um}} / \gamma^{\prime} D$ $=0.42$ and identical $k / \gamma^{\prime}=0.17\left(s_{\mathrm{u}}=10+1 z \mathrm{kPa}\right)$, the maximum heave $h_{\text {in-max }}$ in the heave profile inside the caisson appears adjacent to the caisson wall with stiffeners throughout the full penetration depth of the caisson (see Figure $5 \mathrm{c}$ and Figure 5d). As such, the heave profiles are consistently convex across the caisson inside diameter. This is because higher strength intercept at the mudline $\left(s_{\mathrm{um}}\right)$ can support the upheaving soil between the stiffeners. Hence the soil adjacent to the stiffeners stays vertical rather than caving into the cavity between the stiffeners (see the left figure of Figure 5d). Using Equations 1 and 2, the critical depths can be calculated as $H_{\mathrm{r}} / D=$ 0.88 and $H_{\mathrm{c}} / D=1.0$, which lead to caisson penetrations of $d / D=\left(H_{\mathrm{r}}+w\right) / D=1.38$ and $d / D=\left(H_{\mathrm{c}}+s+h+w\right) / D=2.06$ respectively. The soil heaving rate increases with increasing caisson initial penetration (i.e. $d<1.2 D)$; then reduces to nearly zero $\left(R_{\mathrm{h}} \sim\right.$ 
0 ) when the heave reaches its peak (i.e $d \sim 2.0 D$ ). After the peak heave is reached ( $d>$ $2.0 D$ ), the heaving rate becomes negative (i.e. $R_{\mathrm{h}}<0$; plugging).

Once caisson penetration depth reaches $H_{\mathrm{r}} / D$ and $H_{\mathrm{c}} / D$ (i.e. the corresponding penetration depths of $d=1.38 D$ and $2.06 D$ respectively), soil starts to infill the gaps between the embedded stiffeners (see the right figure of Figure $5 \mathrm{~d}$ ). These critical depths of $H_{\mathrm{r}} / D$ and $H_{\mathrm{c}} / D$ in the stiffer soil are significantly higher than those of softer clay $\left(s_{\mathrm{um}} / \gamma^{\prime} D=0.04\right)$ with corresponding depths $d=0.65 D$ and $1.24 D$ for rotational and cavity failures respectively. Due to the consequent cavity formation between the embedded stiffeners in the stiffer soil, the peak heave height $\left(h_{\text {in-max }}\right)$ is remarkably higher than that in the softer soil at any penetration depth $d$. For instance, for $d / D=$ 0.8 and 2 , the $h_{\text {in-max }}$ of $0.4 \mathrm{~m}, 0.96 \mathrm{~m}$ for the stiffer soil (i.e. high $s_{\mathrm{um}} / \gamma^{\prime} D=0.42$ ) are nearly doubled when compared to the $h_{\text {in-max }}=0.21,0.57$ for the softer soil (i.e. low $\left.s_{\mathrm{um}} / \gamma^{\prime} D=0.04\right)$, and $h_{\mathrm{in}-\max }$ occurs at the center of the caisson in the softer soil (after initial penetration) and near the caisson wall in the stiffer soil.

To quantify the effect of soil strength on the soil heave inside the caisson, the inner heave volume ratio of $R_{\mathrm{vi}}$ are plotted against normalized caisson penetration depth of $d / D$ in Figure 6. Figure 6a shows the influence of the mudline strength intercept $s_{\mathrm{um}}$ or $s_{\mathrm{um}} / \gamma^{\prime} D$, plotting the results for $s_{\mathrm{u}}=1+1 z, 5+1 z, 10+1 z \mathrm{kPa}\left(\right.$ i.e. $s_{\mathrm{um}} / \gamma^{\prime} D=0.04$ $0.21,0.42$; while $k / \gamma^{\prime}$ is constant as 0.17 ). According to Equations 1 and 2, the critical depths of $H_{\mathrm{r}} / D$ and $H_{\mathrm{c}} / D$ increase with increasing $s_{\mathrm{um}} / \gamma^{\prime} D$. The increasing cavity depth of $H_{\mathrm{d}} / D$ means more gaps remains open, and hence the soil flowed inside the caisson heaves up, leading to an increase in soil heave volume ratio for any penetration depth. For instance, the peak $R_{\mathrm{vi}}$ of about $85 \%$ for $s_{\mathrm{um}} / \gamma^{\prime} D=0.04$ increases to $R_{\mathrm{vi}}=170 \%$ for $s_{\mathrm{um}} / \gamma^{\prime} D=0.21$ and $R_{\mathrm{vi}}=190 \%$ for $s_{\mathrm{um}} / \gamma^{\prime} D=0.42$. The peak heave volume ratios are 
also appearing at greater depths for higher $s_{\mathrm{um}} / \gamma^{\prime} D$, which is also corresponding to the higher $H_{\mathrm{c}} / D$ since soil plugging starts after the soil fills the gaps between the embedded stiffeners. It should be noted that the large heave volume ratio of $R_{\mathrm{vi}}>$ $100 \%$ is mainly because of the calculated soil volume displaced by the penetrating caisson does not take into account the formed cavities between the embedded stiffeners (see Figures $4 \mathrm{~b}$ and $5 \mathrm{~d}$ ).

The effect of the soil strength gradient, $k$ or $k / \gamma^{\prime}$ on the inner heave is demonstrated in Figure $6 \mathrm{~b}$ for a range of $k / \gamma^{\prime}$ of $0.17,0.33,0.5$; but with identical normalized strength respectively of $s_{\mathrm{um}} / \gamma^{\prime} D=0.04$ (left graph of Figure 6b), 0.21 (middle graph of Figure 6b) and 0.42 (right graph of Figure 6b). It can be seen that inner heave ratio is higher for higher with higher $k / \gamma^{\prime}$ for full penetration depths in all cases. However, compared to the effect of $s_{\mathrm{um}} / \gamma^{\prime} D$, the difference in $R_{\mathrm{iv}}$ due to different $k / \gamma^{\prime}$ is very marginal. This indicates that the effect of $s_{\mathrm{um}} / \gamma^{\prime} D$ is more prominent, relative to $k / \gamma^{\prime}$.

In order to explore the effect of soil undrained shear strength on the maximum heave height across the caisson diameter, $h_{\text {in-max }} / D$, the results of various combinations of normalized strength $s_{\mathrm{um}} / \gamma^{\prime} D=0.04,0.21,0.42$ and soil strength non-homogeneity $k / \gamma^{\prime}$ of $0.17,0.33,0.5$ are plotted in Figure 7 along the normalized caisson penetration depth. These profiles echo the previous discussion in terms of $R_{\mathrm{vi}}$ with higher heave height for higher $s_{\mathrm{um}}$. No clear trend can be drawn. This means that both $s_{\mathrm{um}} / \gamma^{\prime} D$ and $k D / s_{\text {um }}$ affect $h_{\text {in-max }} / D$ profile simultaneously.

For common marine clay deposits, the values of $E / s_{\mathrm{u}}$ lie in the range of $150 \sim 500$. Additional investigation was therefore carried out to investigate the effect of $E / \mathrm{s}_{\mathrm{u}}$ on inner soil heave. The results show that $h_{\text {in-max }} / D$ increases with increasing $E / s_{\mathrm{u}}$, with the effect being $<8 \%$ as $E / s_{\mathrm{u}}$ increases from 150 to 500 . As such, there is no further 
study conducted.

\section{Effect of Caisson Geometry $(D /(b+t))$}

To examine the influence of $D /(t+b)$ on the soil heave, three groups of analyses have been carried by varying the thickness of the caisson skirt, $t$ (Group IV, Table 2), the caisson diameter, $D$ (Group V, Table 2), and the width of the stiffeners, $b$ (Group VI, Table 2), giving the ratio $D /(t+b)$ of $20,22.9,23.5 ; 20,40,50$; and 16, 11.4, 8.9; respectively, while soil normalized strength and non-homogeneity are $s_{\mathrm{um}} / \gamma^{\prime} D, k / \gamma^{\prime}=$ (0.21), (0.17); (0.042, 0.021, 0.017), (0.17); (0.625), (0.33), respectively $(w=2 \mathrm{~m}, s=$ $2 \mathrm{~m})$.

Figure 8a shows corresponding effect on maximum heave height $h_{\text {in-max }} / D$ along the caisson normalized penetration depth for Group IV (Table 2) analyses. For the soil with identical $s_{\mathrm{um}} / \gamma^{\prime} D=0.21$ and $k / \gamma^{\prime}=0.17$, the soil does not tend to flow back into the gaps between the embedded stiffeners, instead flows vertically upward to the surface. The cavity depth is higher for lower $D /(t+b)$ (Zhou et al. 2016). This is because the lower $D /(t+b)$ yields lower lateral pressure or delayed soil infill into the gaps, resulting in more upward flow. This phenomenon is commonly identified for open-ended driven piles (API 2007). This delayed soil backflow augments $H_{\mathrm{r}} / D$ and $H_{\mathrm{c}} / D$, as can also be seen in Equations 1 and 2. Consequently, the maximum heave height is greater for lower $D /(t+b)$ at any penetration depth. Furthermore, for these cases, the lower $D /(t+b)$ was set up by increasing the skirt thickness, $t$, and hence the volume of the embedded caisson or inward soil displacement is increased to generate a higher $h_{\text {in-max }} / D$. For instance, the peak heave of $h_{\text {in-max }} / D=0.12$ is obtained for $D /(t+b)=23.5$. When $D /(t+b)$ is reduced to 20 , the peak heave is increased to $h_{\text {in- }}$ $\max / D=0.175$ (i.e. by 1.5 times). However, both peaks are attained at a similar 
penetration depth of $d / D=\sim 1.6$.

The reverse trend can be observed when the same results plotted in terms of heave volume ratio $R_{\mathrm{vi}}$, as illustrated in Figure $8 \mathrm{~b}$. The values of $R_{\mathrm{vi}}$ are lower for lower $D /(t+b)$. This is because, at any given penetration depth, the volume of the embedded caisson increases with lower $D /(t+b)$ (or higher $t$ ). This higher volume of the embedded caisson was used to normalize the inner heave volume producing a lower $R_{\mathrm{vi}}$

Figure 9 shows the effect of $D /(t+b)$ with various caisson diameter (Group V in Table 2). The soil normalized strength also varies as $s_{\mathrm{um}} / \gamma^{\prime} D=0.042,0.021,0.017\left(s_{\mathrm{u}}=1+\right.$ $1 z \mathrm{kPa}$ ), although the soil strength non-homogeneity $k / \gamma^{\prime}$ is constant of 0.17 . The results in terms of maximum heave height are shown in Figure 9a, echoing the findings of Figure $8 \mathrm{a}-$ higher $h_{\text {in-max }} / D$ for lower $D /(t+b)$. However the peak appears at different depths - deeper for lower $D /(t+b)$. Figure $9 \mathrm{~b}$ plots the profiles of inner heave volume ratio, indicating the reverse trend of Figure $8 \mathrm{~b}$ - higher $R_{\mathrm{vi}}$ for lower $D /(t+b)$. These are because, for a given penetration depth, embedded caisson volume is higher for greater diameter, but the reverse is true for critical depths of rotational flow and open cavity (see Equations 1 and 2).

A comparison of evolution of maximum soil heave with the progress of caisson penetration for $D /(t+b)=16,11.4,8.9$; which were obtained by varying $b(b=0.2 \mathrm{~m}$, $0.3 \mathrm{~m}, 0.4 \mathrm{~m})$; is shown in Figure $10\left(s_{\mathrm{u}}=15+2 z \mathrm{kPa} ; s_{\mathrm{um}} / \gamma^{\prime} D=0.625, k / \gamma^{\prime}=0.33\right)$. Wider stiffeners affect soil heaving in two respects. First, the volume of caisson inner structure penetrating the ground increases, leading to more soil to be displaced and increasing soil heave. Second, the size of the gaps between the embedded stiffeners increases, resulting in again more soil to be displaced and more soil required to fill in 
the gaps. The resultant is higher $h_{\text {in,max }} / D$ for lower $D /(t+b)$ (i.e. higher $\left.b / t\right)$ at any penetration depth.

\section{Effect of Interface Friction Coefficient $(\alpha)$}

The results of all penetration analyses presented so far have been obtained considering skirt- and stiffeners-soil interface friction coefficient $\alpha=0.2$. Analyses have also been performed considering $\alpha=0.4$ (Group VII, Table 2) to examine the effect of interface roughness on the resulting soil heave. Figure 12 shows the effect of soil-caisson friction coefficient $\alpha$ on inner soil heave in a soft clay of $s_{\mathrm{u}}=1+1 z \mathrm{kPa}\left(s_{\mathrm{um}} / \gamma^{\prime} D=\right.$ $\left.0.04, k / \gamma^{\prime}=0.17\right)$ and in a stiff clay of $s_{\mathrm{u}}=10+1 z \mathrm{kPa}\left(s_{\mathrm{um}} / \gamma^{\prime} D=0.42, k / \gamma^{\prime}=0.17\right)$. Apparently, with increasing soil-caisson friction, the friction force along the caisson stiffeners and the inner soil is increased. However, opposite trends of $\alpha$ effect on $h_{\text {in- }}$ ${ }_{\max } / D$ are found in different soils. In the soft soil $\left(s_{\mathrm{u}}=1+1 z \mathrm{kPa}\right), h_{\mathrm{in}-\max } / D$ is increased with higher $\alpha$; and in the stiff soil $\left(s_{\mathrm{u}}=10+1 z \mathrm{kPa}\right)$ the reverse is observed. This is due to the heave profile inside the caisson: concave in soft soil and convex in stiff soil (see Figure 5). In the soft soil, the concave heave profile will increase the $h_{\text {in- }}$ ${ }_{\max } / D$ at the caisson center due to the "drag down" effect from the caisson side. However, in the stiff soil, the heave profile is convex with $h_{\text {in-max }} / D$ appearing near the caisson wall. The "drag down" due to the friction therefore decreases $h_{\text {in-max }} / D$. The difference in $h_{\text {in-max }} / D$ in the range studied $(\alpha=0.2,0.4)$ is minimal.

\section{Effective Unit Weight of Soil ( $\gamma$ )}

In the above analyses, the effective unit weight was considered as $\gamma^{\prime}=6 \mathrm{kN} / \mathrm{m}^{3}$. A group of analyses were also carried out taking $\gamma^{\prime}=8 \mathrm{kN} / \mathrm{m}^{3}$ to explore the effect of $\gamma^{\prime}$ on inner soil heaving (Group VIII, Table 2). The depths of soil infilling $\left(H_{\mathrm{r}}\right.$ and $H_{\mathrm{c}}$ ) into the gaps between the embedded stiffeners are linked directly to the inverse of $\gamma^{\prime}$ 
(see Equations 1 and 2), since the heave stability reduces with increasing $\gamma^{\prime}$. The effect of $\gamma^{\prime}$ intrinsically discussed previously while discussing the influence of normalized strength $s_{\mathrm{um}} / \gamma^{\prime} D$ and strength non-homogeneity $k / \gamma^{\prime}$. Figure 12 focuses specifically on this issue. The maximum heave height $h_{\text {in-max }} / D$ is plotted for $\gamma^{\prime}=6$ and 8 , and for both soft soil deposit with $s_{\mathrm{u}}=1+1 z \mathrm{kPa}\left(\right.$ or $\left.s_{\mathrm{um}} / \gamma^{\prime} D=0.04,0.03 ; k / \gamma^{\prime}=0.17,0.13\right)$ and stiff soil deposit with $s_{\mathrm{u}}=10+1 z \mathrm{kPa}\left(\right.$ or $\left.s_{\mathrm{um}} / \gamma^{\prime} D=0.42,0.31 ; k / \gamma^{\prime}=0.17,0.13\right)$. In both soils, the trends are consistent - higher $h_{\mathrm{in}-\max } / D$ is associated with lower $\gamma^{\prime}$ or higher $s_{\text {um }} / \gamma^{\prime} D$ and higher $k / \gamma^{\prime}$. The peak is also attained at a similar depth $d / D=\sim 2.45$ (for $s_{\mathrm{u}}=1+1 z \mathrm{kPa}$ ) and $\sim 1.85$ (for $s_{\mathrm{u}}=10+1 z \mathrm{kPa}$ ).

\section{Maximum Inner Soil Heave Height ( $\left.h_{\text {in-max }}\right)$}

The above discussion highlights that four normalized factors related to the soil strength and density, and caisson geometric dimensions and penetration depth dictate the inner soil heave, including $s_{\mathrm{um}} / \gamma^{\prime} D, k / \gamma^{\prime}, D /(t+b)$, and $d / D$. Assembling all the LDFE results, an approximate expression can be developed for assessing the maximum inner soil heave height $h_{\text {in-max }}$ of a suction caisson in clay as

$$
\frac{h_{\text {in-max }}}{D}=3.45\left(\frac{d}{D}\right)^{2.19} \exp \left(-\frac{d}{D}\right)\left(0.68 \frac{k}{\gamma^{\prime}}+\frac{s_{\mathrm{um}}}{\gamma^{\prime} D}\right)^{0.74}\left(\frac{D}{b+t}\right)^{-0.588}
$$

Figure 13 displays some examples showing reasonable prediction of the computed profiles using Equation 3. The measured data from two field installations and two centrifuge tests are also included in Figure 13, with the prediction using Equation 3 shown good agreement. Despite of this consistency with the measured field data and Westgate et al. (2009) reported minimal influence of installation method on inner soil heave (for caisson with ring stiffeners), caution should be taken in using Equation 3 in the field as it has been established based on jacked installation results. 


\section{Guidelines for Field Installation}

A suggested procedure for estimating maximum soil heave inside of an installing caisson is outlined here. The procedure is based on an assumed linearly increasing profile of soil undrained shear strength expressed in terms of the mudline shear strength, $s_{\text {um }}$, and gradient, $k$. The procedure can be modified for more complex strength profiles, maintaining equivalent principles.

Step 1. Determine representative values of the soil parameters $s_{\mathrm{um}}, k$ and effective selfweight, $\gamma^{\prime}$, and hence evaluate the non-dimensional ratios $s_{\mathrm{um}} / \gamma^{\prime} D$ and $k / \gamma^{\prime}$.

Step 2. For the given caisson diameter, $D$, thickness of the skirt, $t$, and stiffeners width, $b$, evaluate the non-dimensional ratios $D /(t+b)$.

Step 3. For each value of normalized penetration, $d / D$, calculate the maximum inner soil heave height, $h_{\text {in-max }}$, using Equation 3.

Careful consideration should also be given to an appropriate choice of shear strength. Considering the relatively low penetration rates of caissons in the field, the shear strength should be that corresponding to very low strain rates (equivalent to a typical laboratory test), and representative of the average shear strength measured in triaxial compression, triaxial extension and simple shear.

The calculated $h_{\text {in-max }}$ will allow the engineers to estimate the installation depth of the caisson (or where the soil heave may be in contact with the caisson lid invert) and hence assess the required skirt length to avoid any penetration refusal. Critically, it should be remembered that for very low mudline strength with $s_{\text {um }} \leq \sim 3 \mathrm{kPa}, h_{\text {in-max }}$ will appear at the center of the caisson and the heave profile across the caisson radius will be concave, whereas for higher mudline strength with $s_{\mathrm{um}}>\sim 3 \mathrm{kPa}, h_{\mathrm{in}-\max }$ will appear adjacent to the face of the stiffeners (or close to the skirt) and the heave profile 20 
across the caisson radius will be convex. This should be taken into account for designing the geometric profile of the caisson's lid invert.

\section{Concluding Remarks}

This paper has reported the results from LDFE analysis using the RITSS method in AFENA, simulating continuous penetration of stiffened caissons from the seabed surface. The aim was at providing insight into the soil heaving inside the caisson in terms of evolution of heave volume ratio and maximum heave height with the progress of caisson installation. The numerical results from this study, combining with existing measured data from centrifuge tests and field data, have led to establish a robust expression (Equation 3) for assessing maximum inner soil heave height in the field. Guidelines were also given for designing the length of the caisson skirt length and the geometric profile of the caisson's lid invert, avoiding potential penetration refusal. The corresponding penetration resistance profiles and evolution of soil flow mechanisms were reported in Zhou et al. (2016).

\section{Acknowledgements}

The research presented here was undertaken with support from the Australian Research Council (ARC) Discovery Grant (DP1096764). The work forms part of the activities of the Centre for Offshore Foundation Systems (COFS), currently supported as a node of the Australian Research Council Centre of Excellence for Geotechnical Science and Engineering and as a Centre of Excellence by the Lloyd's Register Foundation. This work is also supported by China funding Science and Technology Project of POWERCHINA Huadong Engineering Corporation Limited (SD2013-10) ), the Fundamental Research Funds for the Central Universities of China (D2171820) 
and the Water Resource Science and Technology Innovation Program of Guangdong Province (2015-17). This support is gratefully acknowledged. 


\section{Notation}

$b \quad$ width of stiffener

$D \quad$ diameter of caisson

$d \quad$ penetration depth of skirt tip

$d_{\mathrm{b}} \quad$ penetration depth of bottom stiffener

$d_{2} \quad$ penetration depth of $2^{\text {nd }}$ stiffener

F total penetration resistance of caisson

$H_{\mathrm{c}} \quad$ critical depth of soil backflow into gaps above $2^{\text {nd }}$ stiffener

$H_{\mathrm{r}} \quad$ critical depth of rotational soil flow around bottom stiffener

$h \quad$ height of stiffener

$k \quad$ gradient of increase of undrained shear strength with depth

$S$

(edge to edge) spacing between two successive stiffeners

$s_{\mathrm{u}} \quad$ undrained shear strength of soil

$s_{\mathrm{um}} \quad$ undrained shear strength at mudline

$t \quad$ thickness of skirt wall

w distance of bottom stiffener base from skirt tip

$z \quad$ depth below soil surface

$\alpha \quad$ coefficient of interface friction

$\gamma^{\prime} \quad$ effective unit weight of soil 


\section{References}

Andersen, K. H., Andresen, L., Jostad, H. P., and Clukey, E. C. 2004. Effect of skirttip geometry on set-up outside suction anchors in soft clay. Proc., 23rd International Conference on Offshore Mechanics and Arctic Engineering, Vancouver, OMAE2004-51564.

Andersen, K. H., and Jostad, H. P. 2004. Shear strength along inside of suction anchor skirt wall in clay. Proc. Offshore Technology Conference, Offshore Technology Conference, Houston, OTC 16844.

Andersen, K., Murff, J., Randolph, M. F., Clukey, E., Erbrich, C. T., Jostad, H., Hansen, B., Aubeny, C., Sharma, P., and Supachawarote, C. 2005. Suction anchors for deepwater applications. Proc., 1st Int. Symp. on Frontiers in Offshore Geotechnics (ISFOG), Perth, 3-30.

API 2007. API Recommended practice 2A-WSD. American Petroleum Institute.

Carter, J. P., and Balaam, N. P. 1995. AFENA users' manual. Centre for Geotechnical Research, Department of Civil Engineering, University of Sydney, Australia.

Chen, W., and Randolph, M. F. 2007. External radial stress changes and axial capacity for suction caissons in soft clay. Geotechnique, 57(6), 499-511.

Chen, W., Zhou, H., and Randolph, M. F. 2009. Effect of installation method on external shaft friction of caissons in soft clay. Journal of Geotechnical and Geoenvironmental Engineering, 135(5), 605-615.

Clukey, E. C. 2003. Suction caisson soil displacement during installation. Proc., 1st Int. Symp. on Frontiers in Offshore Geotechnics (ISFOG), Perth, 229-233.

Colliat, J-L., Boisard, P., Gramet, J-C., and Sparrevik, P. 1996. Design and installation of suction anchor piles at a soft clay site in the Gulf of Guinea. Proc. Offshore Technology Conference, Offshore Technology Conference, Houston, OTC 8150.

Dendani, H. 2003. Suction anchors: some critical aspects for their design and installation in clayey soils. Proc., Offshore Technology Conference, Offshore Technology Conference, Houston, OTC 15376.

Dendani, H., and Colliat, J.-L. 2002. Girassol: design analysis and installation of the suction anchors." Proc., Offshore Technology Conference, Offshore Technology Conference, Houston, OTC 14209. 
Erbrich, C. T., and Hefer, P. 2002. Installation of the Laminaria suction piles - a case history. Proc., Offshore Technology Conference, Offshore Technology Conference, Houston, OTC 14240.

Fu, D., Bienen, B., Gaudin, C. and Cassidy, M., 2014. Undrained capacity of a hybrid subsea skirted mat with caissons under combined loading. Canadian Geotechnical Journal, 51(8), 934-949.

Gaudin, C., O’Loughlin, C. D., Hossain, M. S., Randolph, M. F., and Colliat, J.-L. 2014. Installation of suction caissons in Gulf of Guinea clay. Proc., 8th Int. Conf. on Physical Modelling in Geotechnics, Perth, 1, 493-499.

Ghosh, S., and Kikuchi, N. 1991. An arbitrary Lagrangian-Eulerian finite element method for large deformation analysis of elastic-viscoplastic solids. Computer Methods in Applied Mechanics and Engineering, 86(2), 127-188.

Herrmann, L. R. 1978. Finite element analysis of contact problems. Journal of the Engineering Mechanics Division, 104(5), 1043-1057.

House, A. R., and Randolph, M. F. 2001. Installation and pull-out capacity of stiffened suction caissons in cohesive sediments. Proc., 11th International Offshore and Polar Engineering Conference, 2, 574-580.

Hu, Y., and Randolph, M. F. 1998. A practical numerical approach for large deformation problems in soil. International Journal for Numerical and Analytical Methods in Geomechanics, 22(5), 327-350.

Iskander, M., El-Gharbawy, S. and Olson, R., 2002. Performance of suction caissons in sand and clay. Canadian geotechnical journal, 39(3), 576-584.

Newlin, J. A. 2003. Suction anchor piles for the Na Kika FDS mooring system. Part 2: Installation performance. Deepwater mooring systems: Concepts, design, analysis, and materials, ASCE, Houston, 55-57.

Randolph, M. F., Gaudin, C., Gourvenec, S. M., White, D. J., Boylan, N., and Cassidy M. J. 2011. Recent advances in offshore geotechnics for deep water oil and gas developments. Ocean Engineering, 38(7), 818-834.

Randolph, M. F., and House, A. R. 2002. Analysis of suction caisson capacity in clay. Proc., Offshore Technology Conference, Offshore Technology Conference, Houston, OTC 14236.

Randolph, M. F., Low, H. E., and Zhou, H. 2007. In situ testing for design of pipeline and anchoring systems. Keynote Lecture, Proc. 6th Int. Offshore Site 
Investigation and Geotechnics Conference: Confronting New Challenges and Sharing Knowledge, London 1, 251-262.

Randolph, M. F., and White, D. J. 2008. Upper-bound yield envelopes for pipelines at shallow embedment in clay. Geotechnique, 58(4), 297-301.

Schroeder, K., Andersen, K. H., and Jeanjean, P. 2006. Predicted and observed intalation behaviour of the Mad Dog anchors. Proc., Offshore Technology Conference, Offshore Technology Conference, Houston, OTC 17950.

Thorel, L., Dendani, H., Garnier, J., Colliat, J. -L., and Rault, G. 2010. Installation process of suction anchors with and without stiffeners in Gulf of Guinea clay: centrifuge modelling. Proc., $7^{\text {th }}$ International Conference on physical Modelling in Geotechnics, Zurich, 2, 1057-1062.

Vásquez, L. F. G., Maniar, D. R., and Tassoulas, J. L. 2010. Installation and axial pullout of suction caissons: numerical modelling. Journal of Geotechnical and Geoenvironmental Engineering, ASCE, 136(8), 1137-1147.

Westgate, Z. J., Tapper, L., Lehane, B. M., and Gaudin, C. 2009. Modelling the installation of stiffened caissons in overconsolidated clay. Proc., ASME 2009 28th International Conference on Ocean, Offshore and Arctic Engineering, American Society of Mechanical Engineers, 119-126.

Zhou, H., and Randolph, M. F. 2006. Large deformation analysis of suction caisson installation in clay. Canadian Geotechnical Journal, 43(12), 1344-1357.

Zhou, M., Hossain, M. S., Hu, Y., and Liu, H. 2016. Installation of stiffened caissons in nonhomogeneous clays. J. Geotechnical and Geoenvironmental Engineering, ASCE, 142(2), 04015079-1-14. 


\section{Number of Figure: 13}

Figure 1. Schematic diagram of stiffened caisson penetration in nonhomogeneous clay

Figure 2. Typical mesh used in LDFE analysis

Figure 3. Validation of LDFE results with existed computed and measured data: (a) Comparison of inner heave volume ratio with numerical results presented by Zhou and Randolph (2006) (Group I, Table 2); (b) Comparison of inner heave height with measured data presented by Westgate et al. (2009) (Group II, Table 2)

Figure 4. Soil heaving mechanism during a caisson penetration in clay (Group III, Table 2): (a) Caisson penetration in seabed with low strength intercept $s_{\mathrm{u}}=1+1 z \mathrm{kPa}\left(s_{\mathrm{um}} / \gamma^{\prime} D=0.04, k / \gamma^{\prime}=0.17, d / D=1.15\right) ;(\mathrm{b})$ Caisson penetration in seabed with high strength intercept $s_{\mathrm{u}}=5+1 z$ $\mathrm{kPa}\left(s_{\mathrm{um}} / \gamma^{\prime} D=0.21, k / \gamma^{\prime}=0.17, d / D=0.62\right)$

Figure 5. Effect of seabed mudline strength intercept, sum, or sum $/ \gamma^{\prime} \mathrm{D}$ on inner soil heave height (Group III, Table 2): (a) su $=1+1 \mathrm{z} \mathrm{kPa}\left(\mathrm{sum} / \gamma^{\prime} \mathrm{D}=\right.$ $\left.0.04, \mathrm{k} / \gamma^{\prime}=0.17\right)$; (b) Inside soil heave $(\mathrm{su}=1+1 \mathrm{z})($ Axis: $\mathrm{m})(\mathrm{c}) \mathrm{su}=$ $10+1 \mathrm{z}\left(\mathrm{sum} / \gamma^{\prime} \mathrm{D}=0.42, \mathrm{k} / \gamma^{\prime}=0.17\right) ;(\mathrm{d})$ Inside soil heave $(\mathrm{su}=10+1 \mathrm{z})$ (Axis: $\mathrm{m}$ )

Figure 6. Effect of normalized strength, $s_{\mathrm{um}} / \gamma^{\prime} D$, and soil strength nonhomogeneity, $k / \gamma^{\prime}$, on inner soil heave volume ratio (Group III, Table 2): (a) Effect of $s_{\text {um }} / \gamma^{\prime} D: k=1 \mathrm{kPa} / \mathrm{m}$ and $s_{\mathrm{um}}=1,5,10 \mathrm{kPa}$; (b) Effect of $k / \gamma^{\prime}: k=1,2,3 \mathrm{kPa} / \mathrm{m}$

Figure 7. Effect of normalized strength, $s_{\mathrm{um}} / \gamma^{\prime} D$, and soil strength nonhomogeneity, $k / \gamma^{\prime}$, on maximum soil heave height (Group III, Table 2): (a) Effect of $s_{\text {um }} / \gamma^{\prime} D: k=1 \mathrm{kPa} / \mathrm{m}$ and $s_{\text {um }}=1,5,10 \mathrm{kPa}$; (b) Effect of $k / \gamma^{\prime}: k=1,2,3 \mathrm{kPa} / \mathrm{m}$

Figure 8. Effect of caisson diameter ratio, $D /(b+t)$ (varying $t$ ), on inner soil heave $\left(D=4 \mathrm{~m}, s_{\mathrm{u}}=5+1 z \mathrm{kPa}\right.$; Group IV, Table 2): (a) Maximum soil heave height; (b) Inner heave volume ratio

Figure 9. Effect of caisson diameter ratio, $D /(b+t)$ (varying $D)$, on inner soil heave $\left(t=0.05 \mathrm{~m}, s_{\mathrm{u}}=1+1 z \mathrm{kPa}\right.$; Group V, Table 2): (a) Inner maximum heave height; (b) Inner heave volume ratio

Figure 10. Effect of caisson stiffener width (varying $b$ ) on inner soil heave $(t=$ $0.05 \mathrm{~m}, s_{\mathrm{u}}=15+2 z \mathrm{kPa}$; Group VI, Table 2)

Figure 11. Effect of interface friction coefficient, $\alpha$, on inner maximum heave height ( $D=4 \mathrm{~m}, t=0.05 \mathrm{~m}$; Group VII, Table 2)

Figure 12. Effect of soil effective unit weight, $\gamma^{\prime}$, on inner maximum heave height ( $D=4 \mathrm{~m}, t=0.05 \mathrm{~m}$; Group VIII, Table 2)

Figure 13. Design chart for inner soil heave 
Table 1. Summary of measured soil heave inside caisson from case histories and centrifuge tests

\begin{tabular}{|c|c|c|c|c|c|c|c|c|c|c|}
\hline $\begin{array}{c}s_{\mathrm{um}} \\
(\mathbf{k P a})\end{array}$ & $\begin{array}{c}k \\
(\mathrm{kPa} / \mathrm{m})\end{array}$ & $\begin{array}{c}D \\
(\mathbf{m})\end{array}$ & $\begin{array}{c}L \\
(\mathbf{m})\end{array}$ & $\begin{array}{c}t \\
(\mathrm{~m})\end{array}$ & $\begin{array}{c}b \\
(\mathrm{~m})\end{array}$ & $S_{\mathrm{t}}$ & $\begin{array}{c}d \\
(\mathrm{~m})\end{array}$ & $h_{\text {in }}(\mathrm{m})$ & $\begin{array}{c}\text { Field/ } \\
\text { centrifuge }\end{array}$ & Notes \\
\hline 2.22 & 1.26 & 4.5 & 17.3 & 0.02 & 0.4 & 2.75 & 16.5 & 0.8 & \multirow{3}{*}{$\begin{array}{l}\text { Girassol, } \\
\text { offshore } \\
\text { Angola }\end{array}$} & \multirow{3}{*}{$\begin{array}{l}\text { Penetration } \\
\text { refusal; Dendani } \\
\text { and Colliat } \\
(2002)\end{array}$} \\
\hline 2.22 & 1.26 & 5 & 18 & 0.02 & 0.2 & 2.75 & 16.4 & 1.6 & & \\
\hline 2.22 & 1.26 & 5 & 16.1 & 0.02 & 0.2 & 2.75 & 14.5 & 1.6 & & \\
\hline 10 & 1.8 & 5.5 & - & 0.02 & 0.165 & 2.8 & 12.2 & $0.9 \sim 1.5$ & $\begin{array}{l}\text { Laminaria, } \\
\text { offshore } \\
\text { Australia }\end{array}$ & $\begin{array}{l}\text { Penetration } \\
\text { refusal; Erbrich } \\
\text { and Hefer (2002) }\end{array}$ \\
\hline 2.25 & 0.79 & 6.4 & 30.5 & 0.051 & - & 3.5 & 29.5 & 1 & $\begin{array}{l}\text { Diana, Gulf of } \\
\text { Mexico }\end{array}$ & \multirow{3}{*}{$\begin{array}{l}\text { No refusal; } \\
\text { Andersen et al. } \\
\quad(2005)\end{array}$} \\
\hline 0 & 1.45 & 3.7 & 18.3 & 0.046 & 0.0254 & 2.75 & 17.85 & 0.45 & $\begin{array}{l}\text { Marlin, Gulf of } \\
\text { Mexico }\end{array}$ & \\
\hline 2.5 & 1.5 & $4.5 \sim 4$ & 12.3 & 0.015 & 0.1 & 3.3 & & $-1 \sim-1.5$ & $\begin{array}{c}\text { Nkossa, Gulf } \\
\text { of Guinea }\end{array}$ & \\
\hline 0 & 1.3 & 8 & 24 & 0.05 & 0 & 1.8 & 22.4 & 1.6 & \multirow[t]{8}{*}{ Centrifuge test } & \multirow{4}{*}{$\begin{array}{c}\text { Penetration } \\
\text { refusal; Thorel et } \\
\text { al. }(2010)\end{array}$} \\
\hline 0 & 1.3 & 8 & 24 & 0.05 & 0 & 1.8 & 23.3 & 0.7 & & \\
\hline 0 & 1.3 & 8 & 24 & 0.05 & 0.5 & 1.8 & 23.2 & 0.8 & & \\
\hline 0 & 1.3 & 8 & 24 & 0.05 & 0.5 & 1.8 & 22.8 & 1.2 & & \\
\hline 1.33 & 1.2 & 8 & 24 & 0.08 & 0.5 & 1.8 & 23.2 & 0.2 & & $\begin{array}{l}\text { Penetration } \\
\text { refusal; Gaudin } \\
\text { et al. (2014) }\end{array}$ \\
\hline 1 & 2.8 & 3.48 & 14.4 & 0.06 & 0.06 & 2.8 & 13.46 & 0.94 & & \multirow{3}{*}{$\begin{array}{l}\text { Penetration } \\
\text { refusal; Chen et } \\
\text { al. (2009) }\end{array}$} \\
\hline 1 & 1.64 & 3.48 & 14.4 & 0.06 & 0.06 & 2.2 & 13.78 & 0.83 & & \\
\hline 1 & 1.36 & 3.48 & 14.4 & 0.06 & 0.06 & 4.5 & 13.57 & 0.86 & & \\
\hline
\end{tabular}


Table 2. Summary of LDFE analyses performed on non-homogeneous clay

\begin{tabular}{|c|c|c|c|c|c|c|c|c|c|c|}
\hline Analysis & $D / t$ & $D /(t+b)$ & $\begin{array}{c}t \\
(\mathrm{~mm})\end{array}$ & $\begin{array}{c}S_{\text {um }} \\
(\mathrm{kPa})\end{array}$ & $\begin{array}{c}k \\
(\mathrm{kPa} / \mathrm{m})\end{array}$ & $b / t$ & $k / \gamma^{\prime}$ & $s_{\mathrm{um}} / \gamma^{\prime} D$ & $\alpha$ & Notes \\
\hline Group I & 100 & 100.0 & 40 & 4 & 1.5 & - & 0.23 & 0.15 & 0.3 & $\begin{array}{c}\text { Comparison with } \\
\text { numerical result of } \\
\text { Zhou and } \\
\text { Randolph (2007) }\end{array}$ \\
\hline Group II & 226 & 51.4 & 50 & 10 & 2.8 & 3.4 & 0.47 & 0.15 & 0.2 & $\begin{array}{c}\text { Comparison with } \\
\text { centrifuge data of } \\
\text { Westgate et al. } \\
\text { (2009) }\end{array}$ \\
\hline $\begin{array}{l}\text { Group } \\
\text { III }\end{array}$ & $\begin{array}{c}80 \\
80 \\
80 \\
226\end{array}$ & $\begin{array}{c}20 \\
20 \\
20 \\
51.4\end{array}$ & 50 & $\begin{array}{l}1 \\
5 \\
10 \\
5\end{array}$ & $\begin{array}{l}1, \\
2, \\
3 \\
1\end{array}$ & $\begin{array}{c}3 \\
3 \\
3 \\
3.4\end{array}$ & $\begin{array}{l}0.17 \\
0.33 \\
0.50 \\
0.47\end{array}$ & $\begin{array}{l}0.04 \\
0.21 \\
0.42 \\
0.074\end{array}$ & 0.2 & $\begin{array}{l}\text { Investigation of } \\
\text { effect of shear } \\
\text { strength }\end{array}$ \\
\hline $\begin{array}{l}\text { Group } \\
\text { IV }\end{array}$ & $\begin{array}{l}80 \\
160 \\
200\end{array}$ & $\begin{array}{c}20 \\
22.9 \\
23.5\end{array}$ & $\begin{array}{l}50 \\
25 \\
20\end{array}$ & 5 & 1 & $\begin{array}{c}3 \\
6 \\
7.5\end{array}$ & 0.17 & 0.21 & 0.2 & $\begin{array}{l}\text { Investigation of } \\
\text { effect of } \mathrm{D} / \mathrm{t} \text { ratio } \\
\quad(\text { varying } \mathrm{t})\end{array}$ \\
\hline Group V & $\begin{array}{l}80 \\
160 \\
200\end{array}$ & $\begin{array}{c}20 \\
40 \\
50\end{array}$ & 50 & 1 & 1 & 3 & 0.17 & $\begin{array}{l}0.042 \\
0.021 \\
0.017\end{array}$ & 0.2 & $\begin{array}{l}\text { Investigation of } \\
\text { effect of } \mathrm{D} / \mathrm{t} \text { ratio } \\
\quad(\text { varying } \mathrm{D})\end{array}$ \\
\hline $\begin{array}{l}\text { Group } \\
\text { VI }\end{array}$ & 80 & $\begin{array}{c}16 \\
11.4 \\
8.9\end{array}$ & 50 & 15 & 2 & $\begin{array}{l}4 \\
6 \\
8\end{array}$ & 0.33 & 0.625 & 0.2 & $\begin{array}{l}\text { Investigation of } \\
\text { effect of caisson } \\
\text { stiffener width b }\end{array}$ \\
\hline $\begin{array}{l}\text { Group } \\
\text { VII }\end{array}$ & 80 & 20 & 50 & 1,10 & 1 & 3 & 0.17 & $\begin{array}{l}0.04 \\
0.42\end{array}$ & $\begin{array}{l}0.2 \\
, \\
0.4\end{array}$ & $\begin{array}{l}\text { Investigation of } \\
\text { effect of friction } \\
\text { coefficient } \alpha\end{array}$ \\
\hline $\begin{array}{l}\text { Group } \\
\text { VIII }\end{array}$ & 80 & 20 & 50 & 1,10 & 1 & 3 & $\begin{array}{c}0.17, \\
0.13\end{array}$ & $\begin{array}{l}0.04 \\
0.03 \\
0.42 \\
0.31\end{array}$ & 0.2 & $\begin{array}{l}\text { Investigation of } \\
\text { effect of soil unit } \\
\text { weight } \gamma^{\prime}\end{array}$ \\
\hline
\end{tabular}




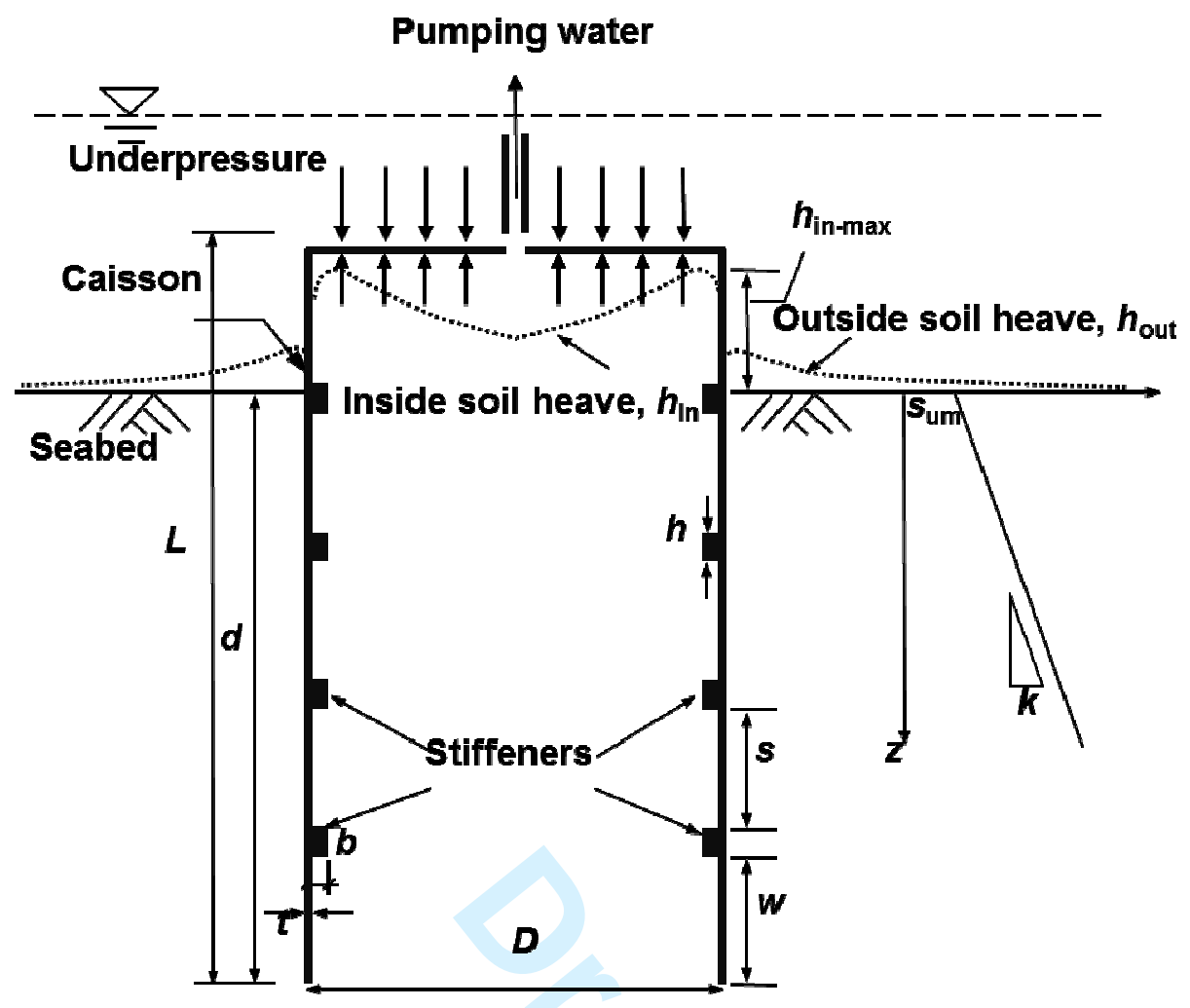

Figure 1. Schematic diagram of stiffened caisson penetration in non-homogeneous clay 


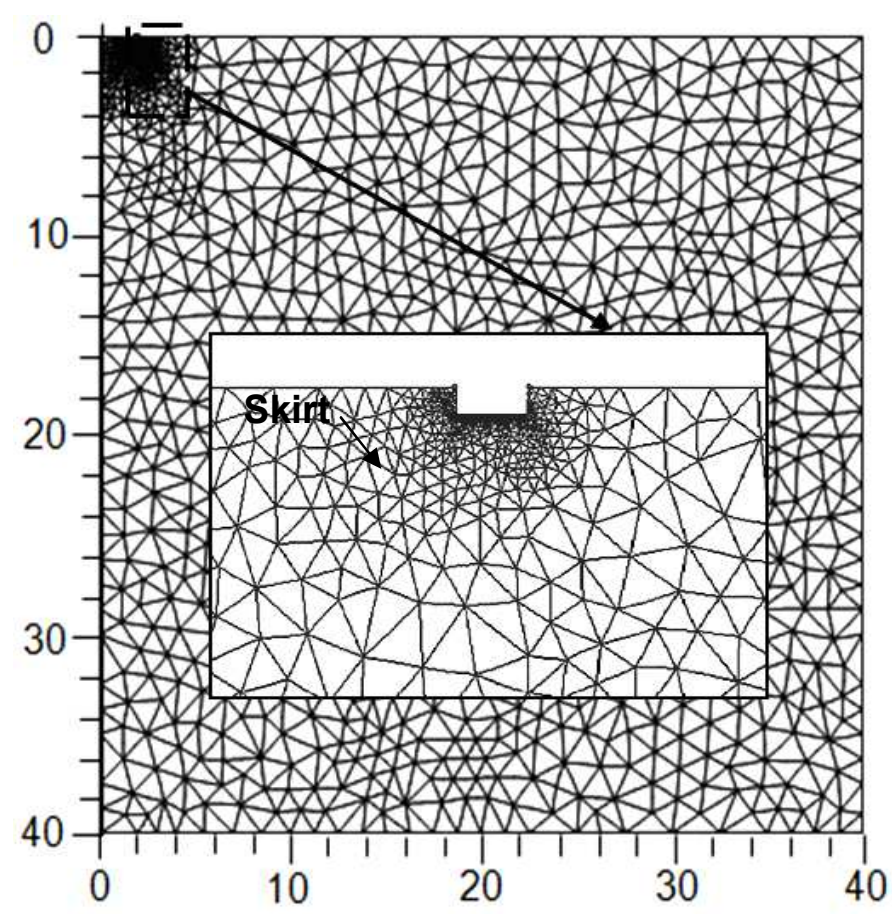

Figure 2. Typical initial mesh used in LDFE analysis 
Inside heave volume ratio, $R_{\mathrm{iv}}(\%)$

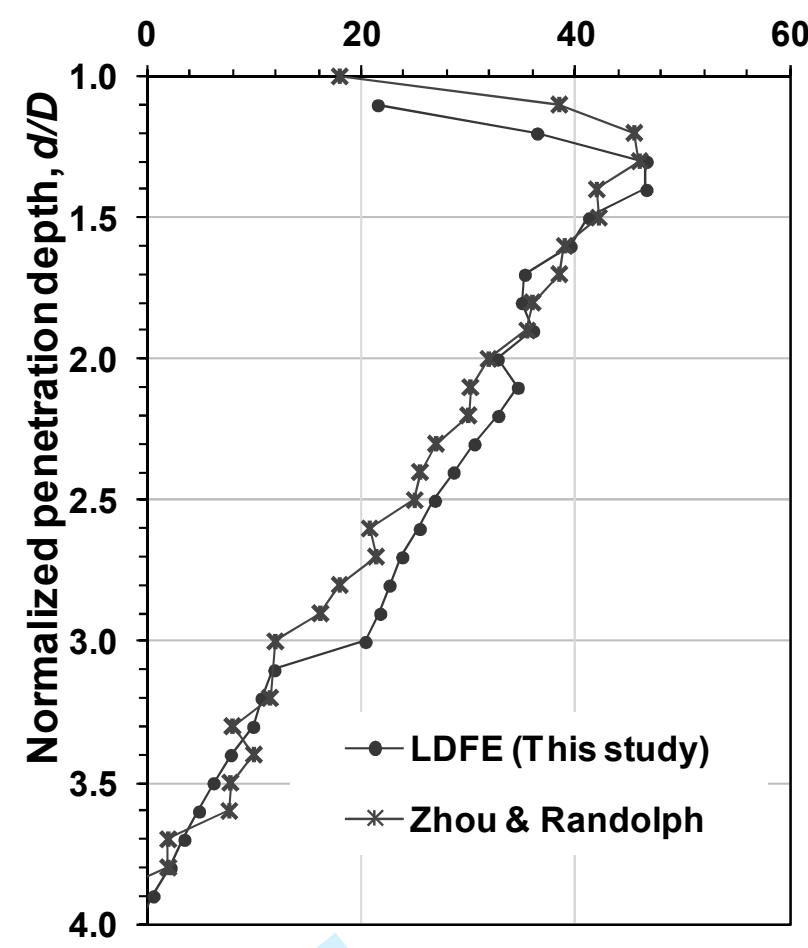

(a) Comparison of inner heave volume ratio with numerical results presented by Zhou and Randolph (2006) (Group I, Table 2)

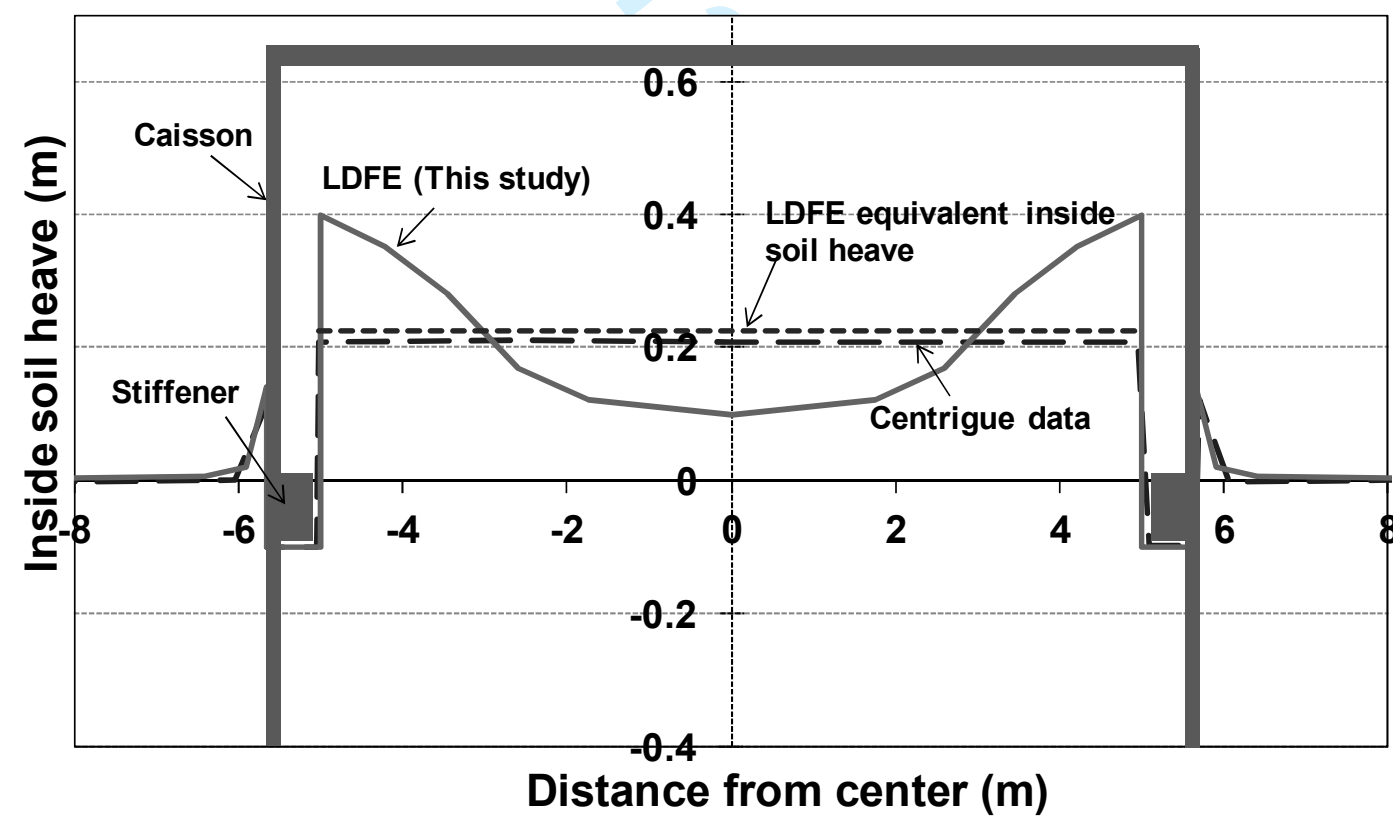

(b) Comparison of inner heave height with measured data presented by Westgate et al (2009) (Group II, Table 2)

Figure 3 Validation of LDFE results with existed computed and measured data 


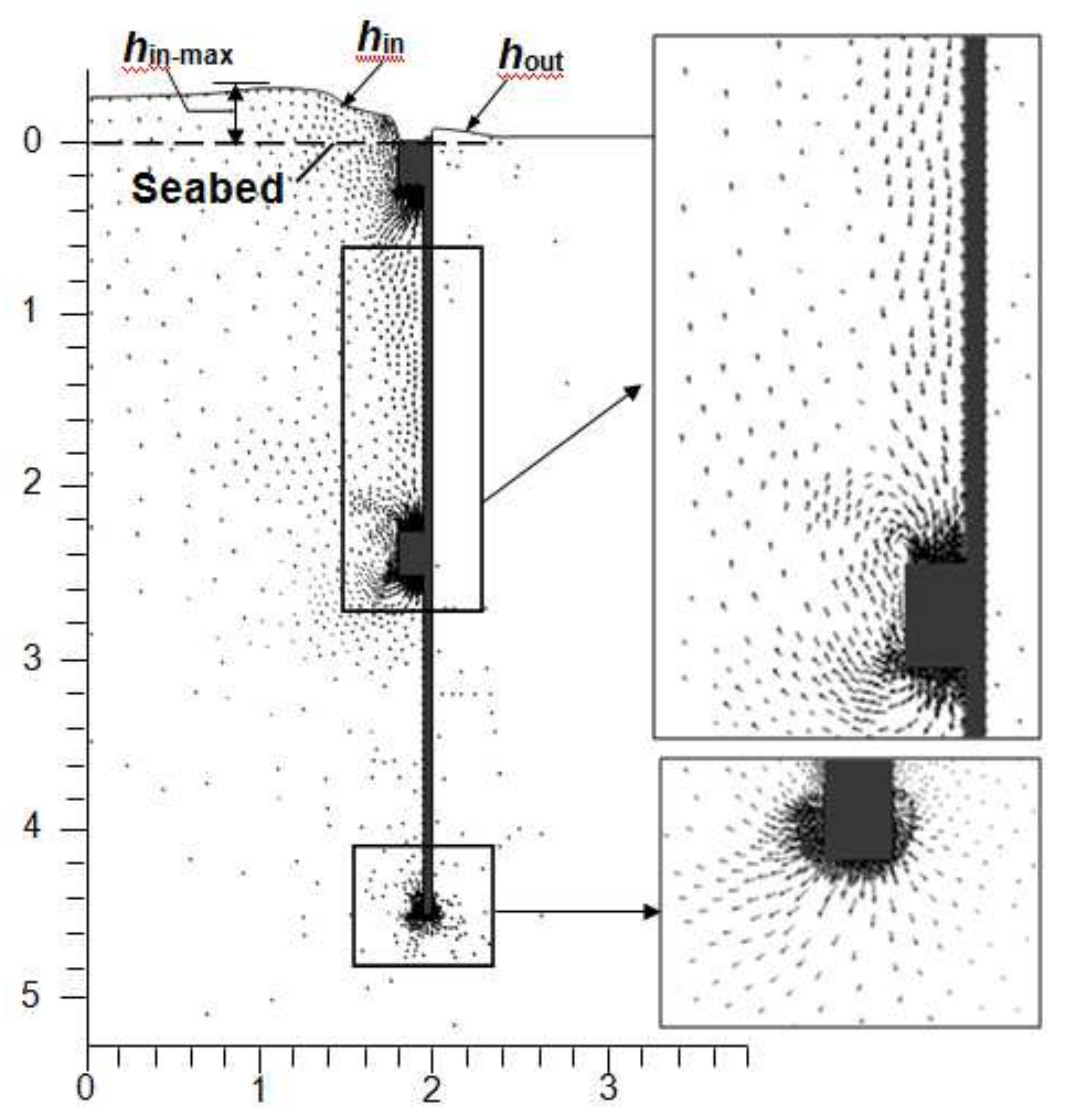

(a) Caisson penetration in seabed with lower strength intercept $s_{\mathrm{u}}=1+1 z \mathrm{kPa}\left(s_{\mathrm{um}} / \gamma^{\prime} D=0.04, k / \gamma^{\prime}\right.$ $=0.17, d / D=1.15)$ 


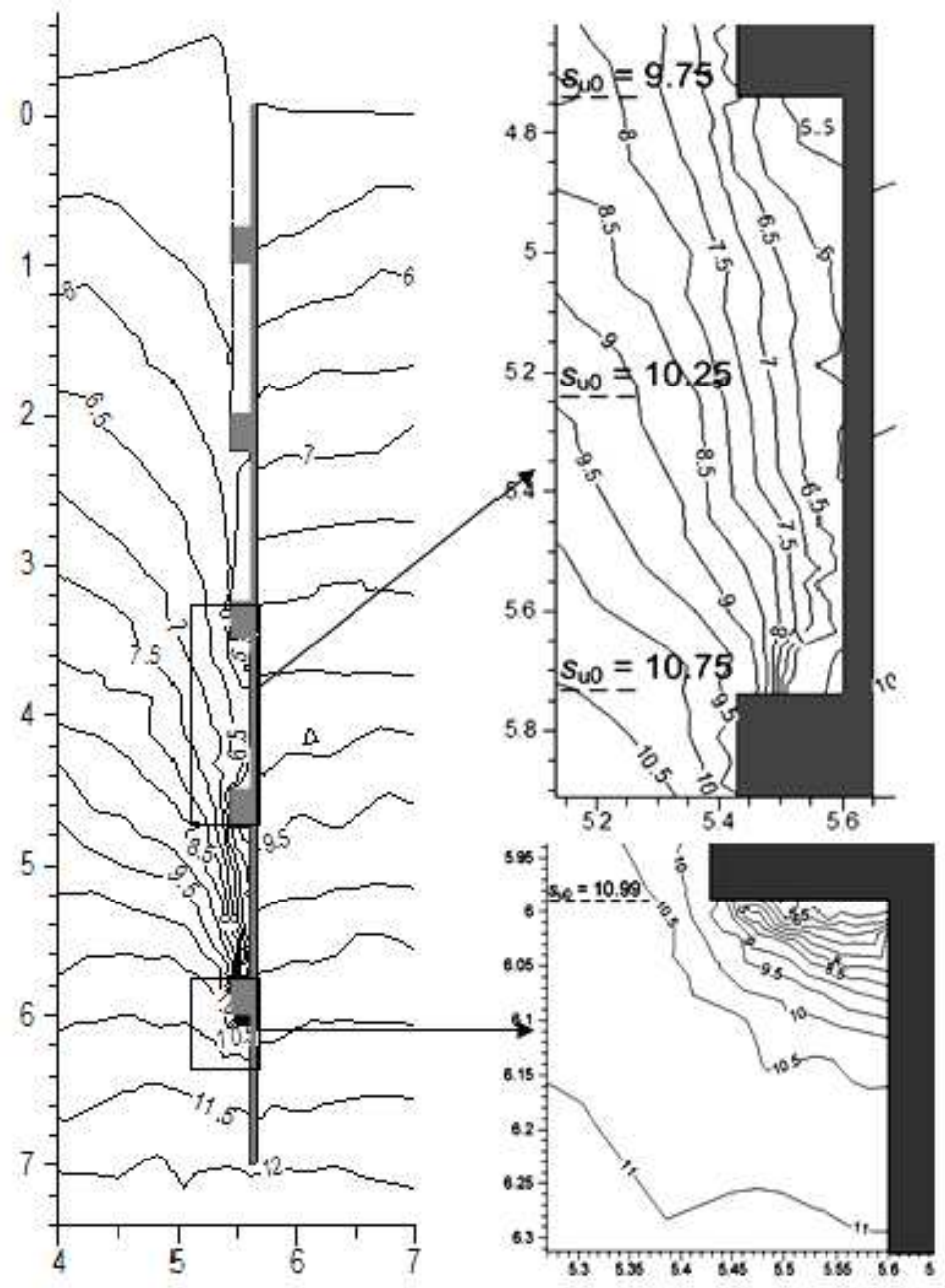

(b) Caisson penetration in seabed with higher strength intercept $s_{\mathrm{u}}=5+1 z \mathrm{kPa}\left(s_{\mathrm{um}} / \gamma^{\prime} D=0.074\right.$, $k / \gamma^{\prime}=0.17, d / D=0.62$ )

Figure 4 Soil heaving mechanism during a caisson penetration in clay (Group III, Table 2) 


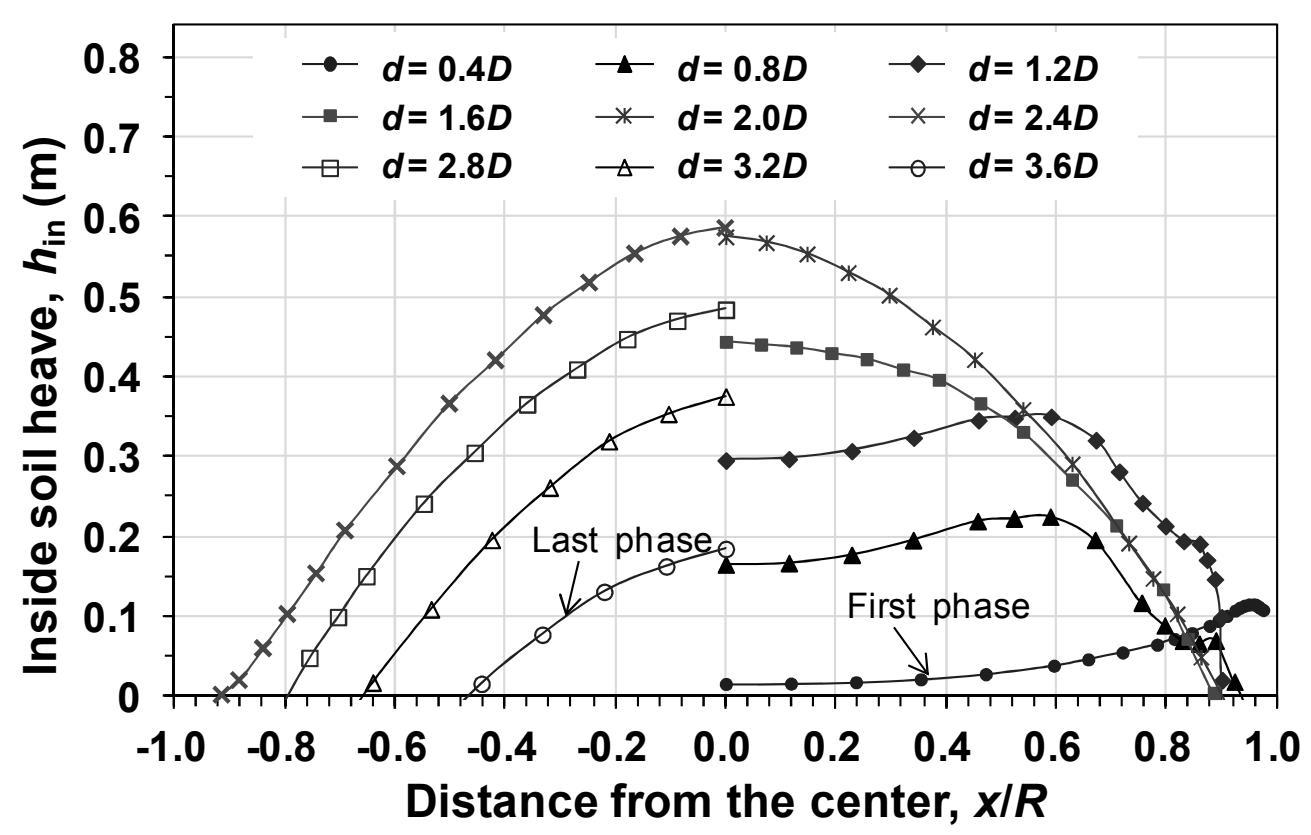

(a) $s_{\mathrm{u}}=1+1 z \mathrm{kPa}\left(s_{\mathrm{um}} / \gamma^{\prime} D=0.04, k / \gamma^{\prime}=0.17\right)$

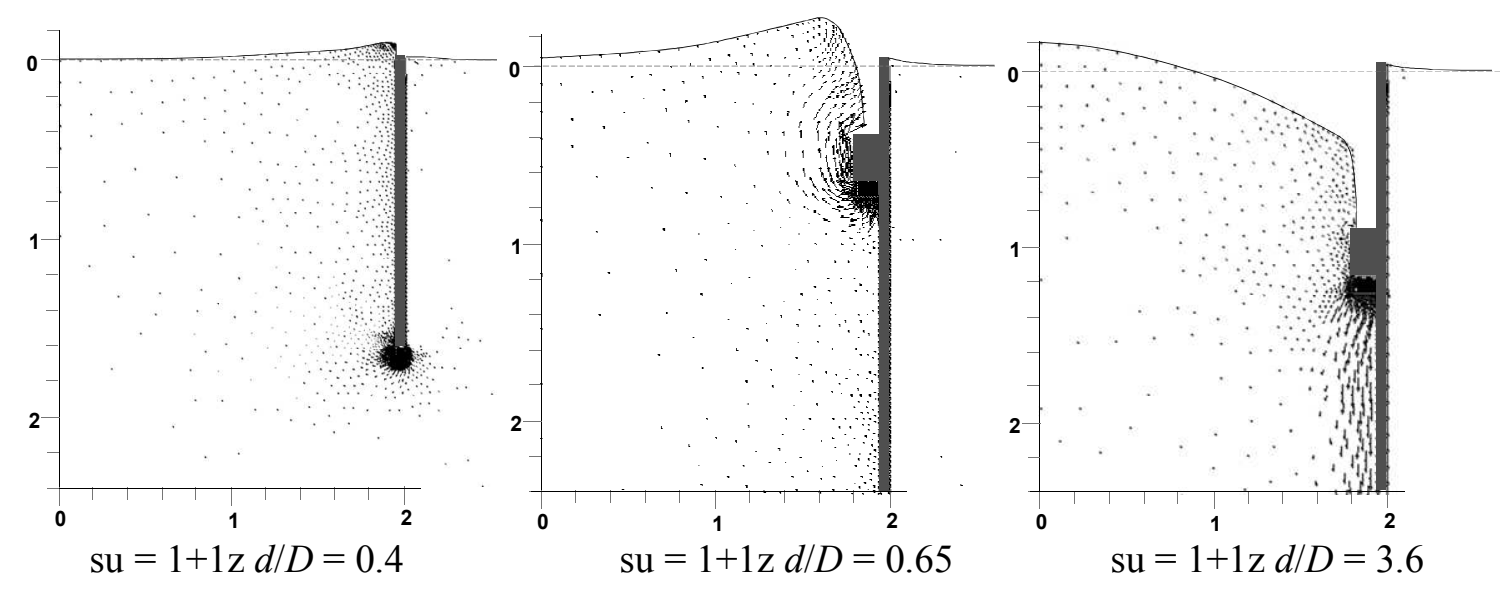

(b) Inside soil heave $\left(s_{u}=1+1 z\right)$ (Axis: $m$ ) 


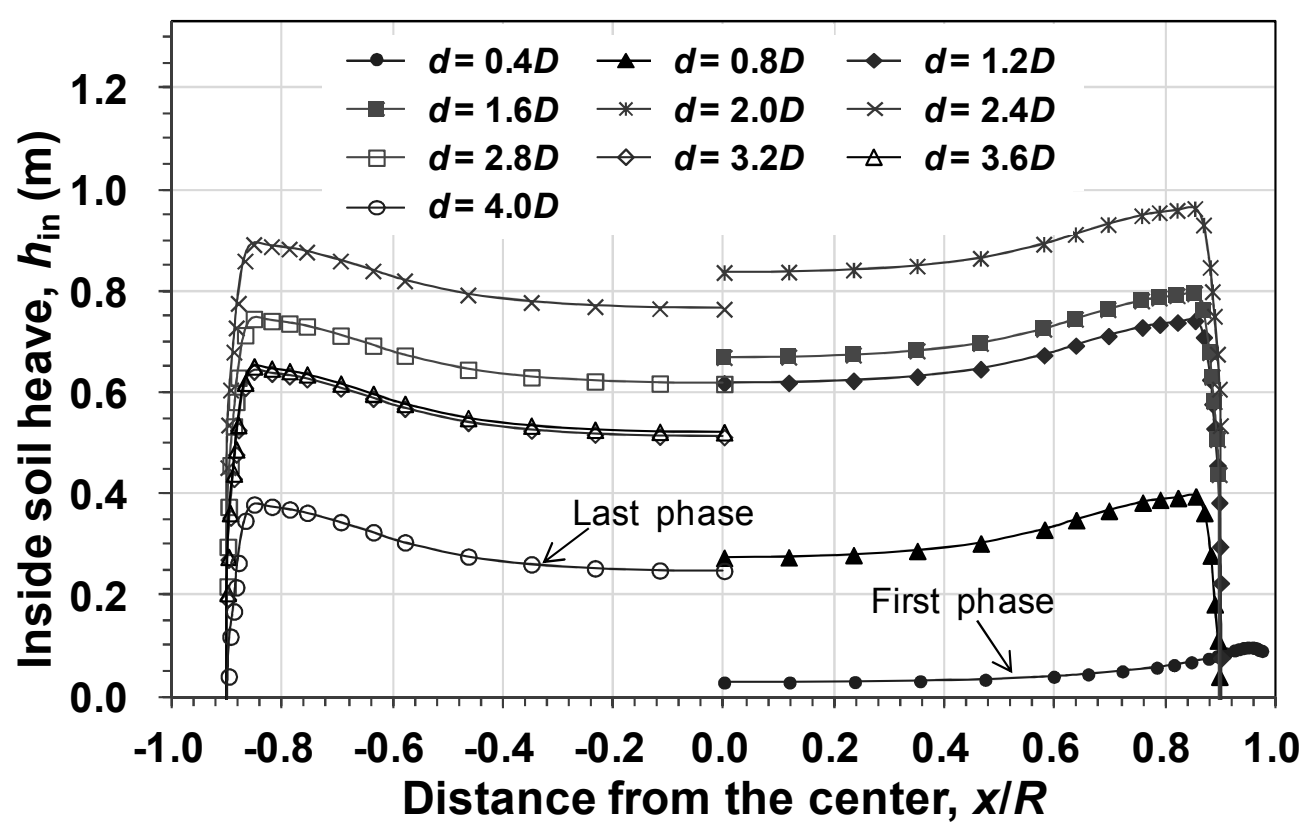

(c) $s_{\mathrm{u}}=10+1 z\left(s_{\mathrm{um}} / \gamma^{\prime} D=0.42, k / \gamma^{\prime}=0.17\right)$
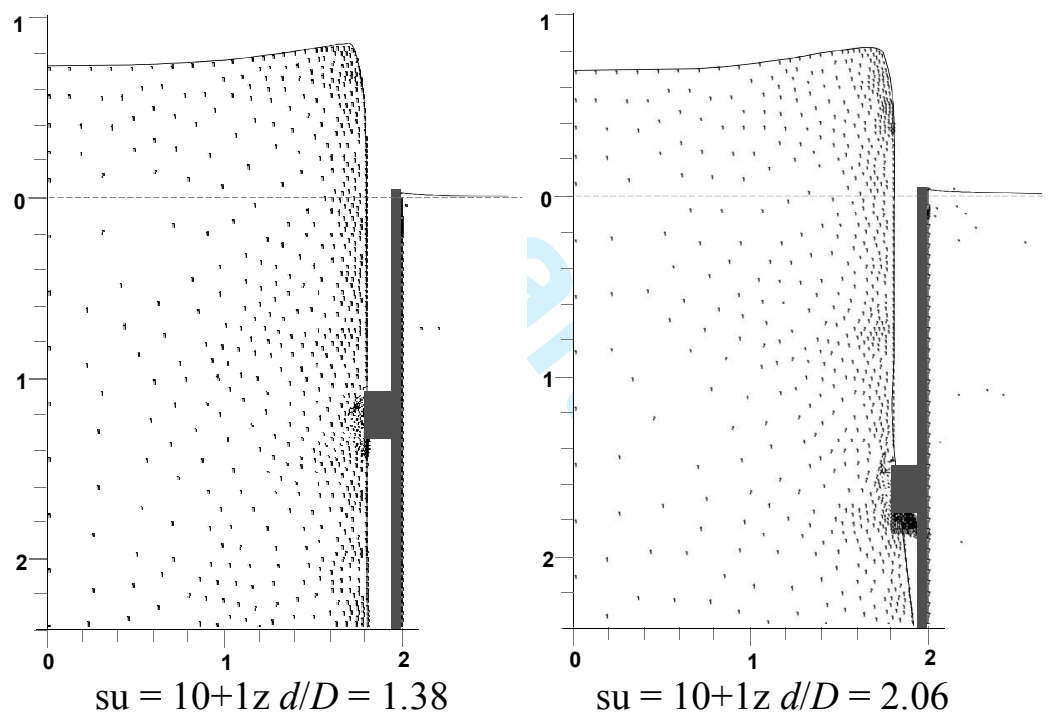

d) Inside soil heave $\left(s_{\mathrm{u}}=10+1 \mathrm{z}\right)$ (Axis: $\left.\mathrm{m}\right)$

Figure 5 Effect of seabed mudline strength intercept, $s_{\mathrm{um}}$, or $s_{\mathrm{um}} / \gamma^{\prime} D$ on inner soil heave height (Group III, Table 2) 


\section{Inside heave volume ratio, $\boldsymbol{R}_{\mathrm{iv}}(\%)$}

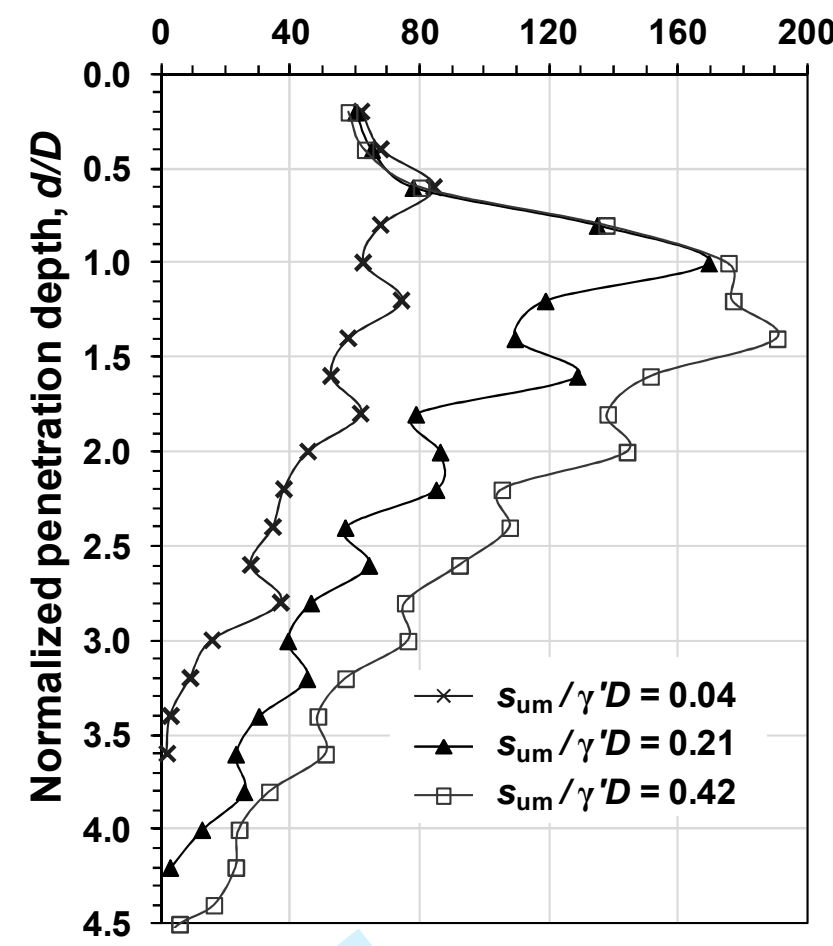

(a) Effect of $s_{\text {um }} / \gamma^{\prime} D: k=1 \mathrm{kPa} / \mathrm{m}$ and $s_{\text {um }}=1,5,10 \mathrm{kPa}$

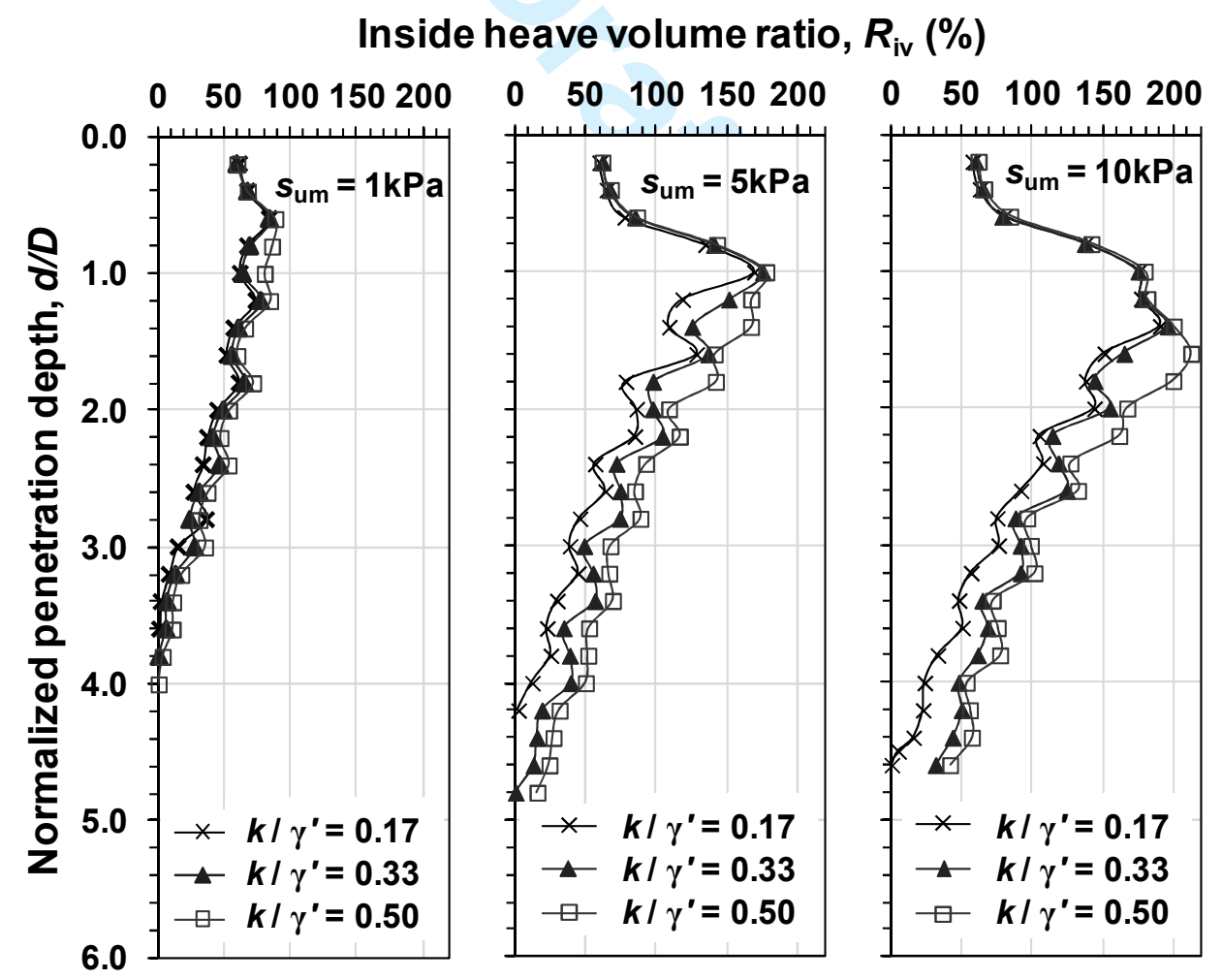

(b) Effect of $k / \gamma^{\prime}: k=1,2,3 \mathrm{kPa} / \mathrm{m}$

Figure 6 Effect of normalized strength, $s_{\mathrm{um}} / \gamma^{\prime} D$, and soil strength non-homogeneity, $k / \gamma^{\prime}$, on inner soil heave volume ratio (Group III, Table 2) 


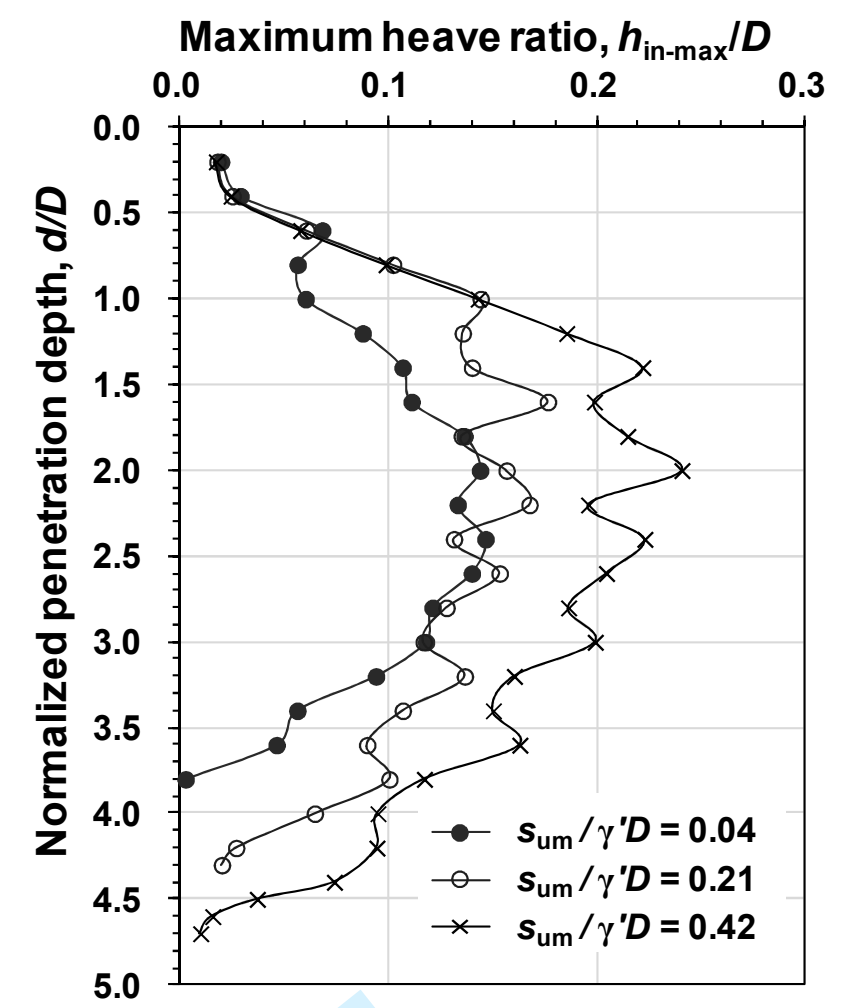

(a) Effect of $s_{\text {um }} / \gamma^{\prime} \mathrm{D}: k=1 \mathrm{kPa} / \mathrm{m}$ and $s_{\text {um }}=1,5,10 \mathrm{kPa}$

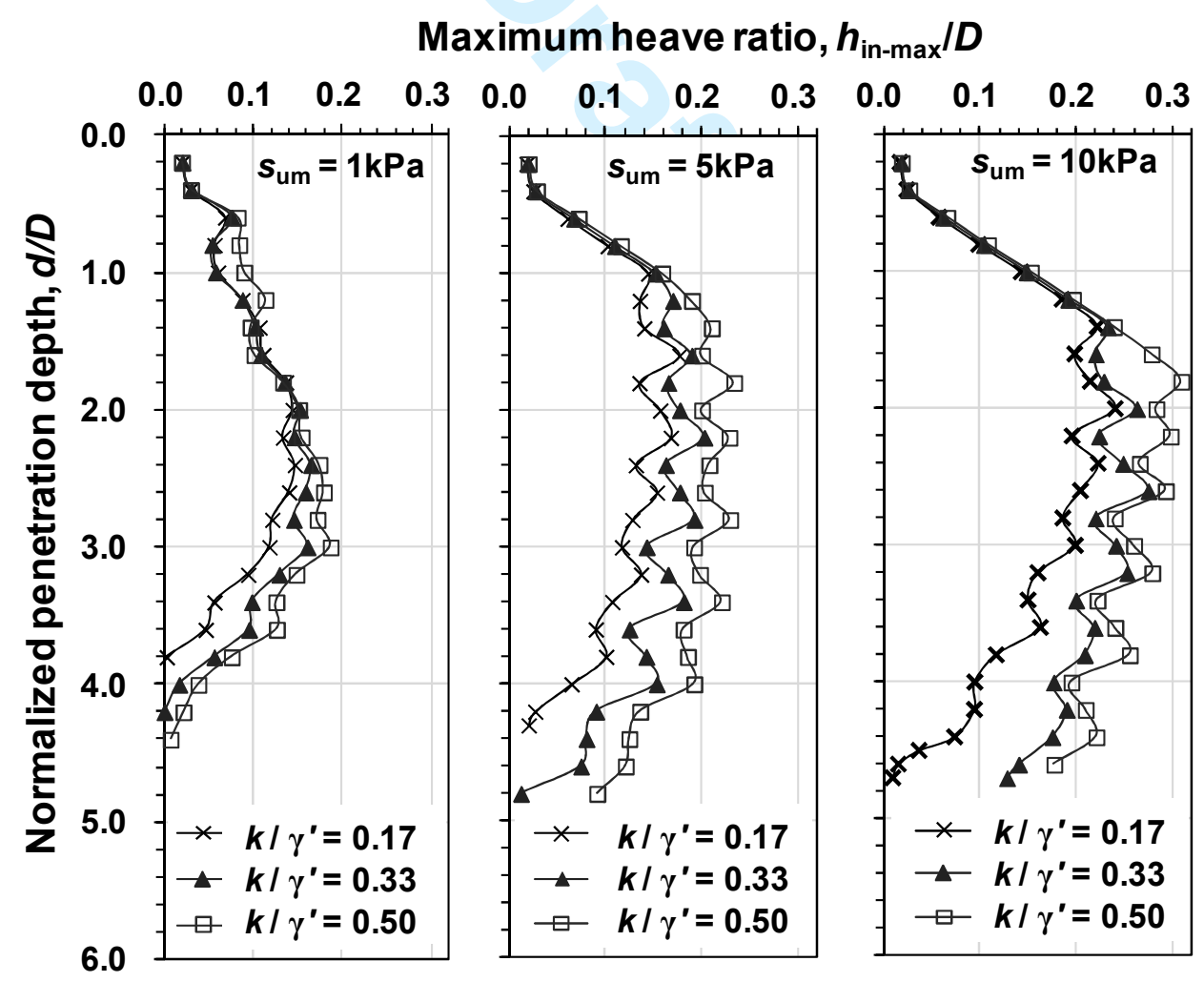

(b) Effect of $k / \gamma^{\prime}: k=1,2,3 \mathrm{kPa} / \mathrm{m}$

Figure 7 Effect of normalized strength, $s_{\mathrm{um}} / \gamma^{\prime} D$, and soil strength non-homogeneity, $k / \gamma^{\prime}$, on maximum soil heave height (Group III, Table 2) 


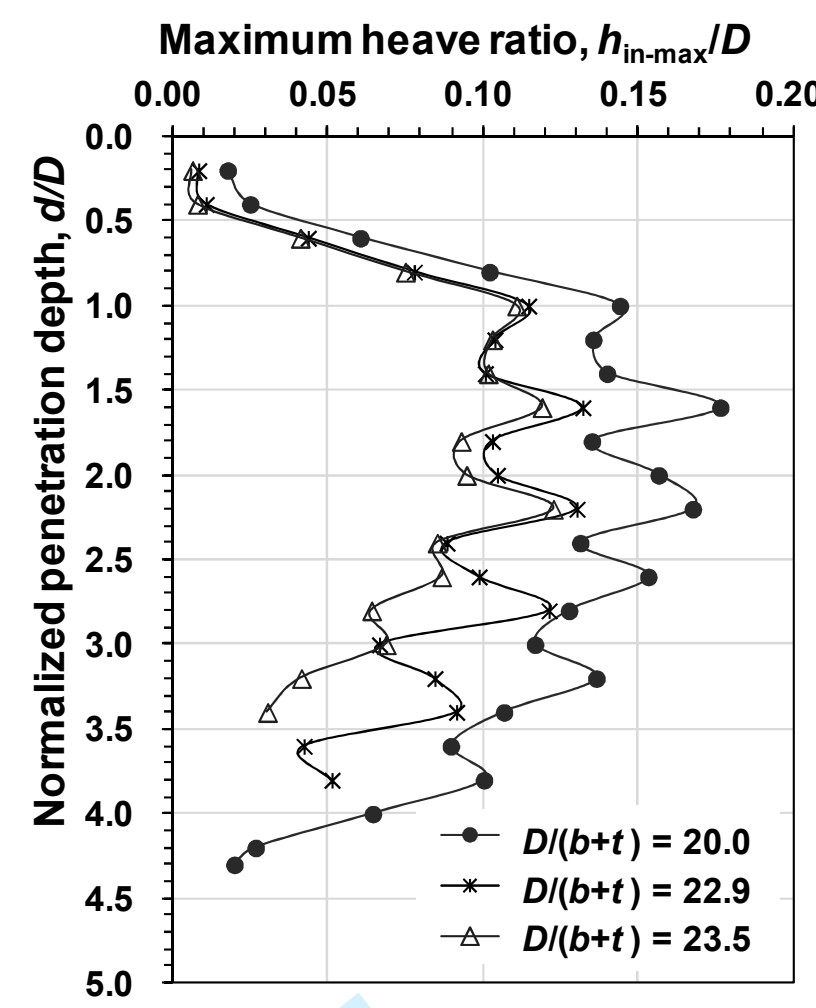

(a) Effect of $D /(b+t)$ on maximum soil heave height: $D=4 \mathrm{~m}, b=150 \mathrm{~mm}$ (varying $t$ )

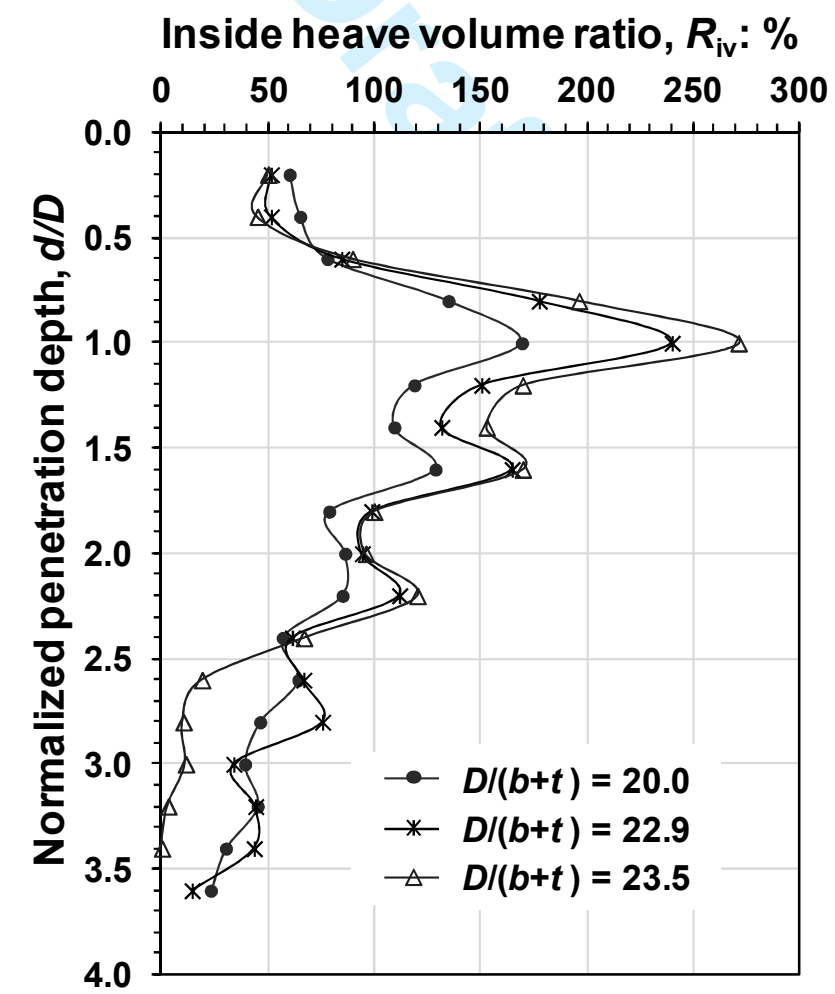

(b) Effect of $D /(b+t)$ on inner heave volume ratio: $D=4 \mathrm{~m}, b=150 \mathrm{~mm}$ (varying $t$ )

Figure 8 Effect of caisson diameter ratio, $D /(b+t)$ (varying $t)$, on inner soil heave $\left(D=4 \mathrm{~m}, s_{\mathrm{u}}\right.$ $=5+1 z \mathrm{kPa}$; Group IV, Table 2) 


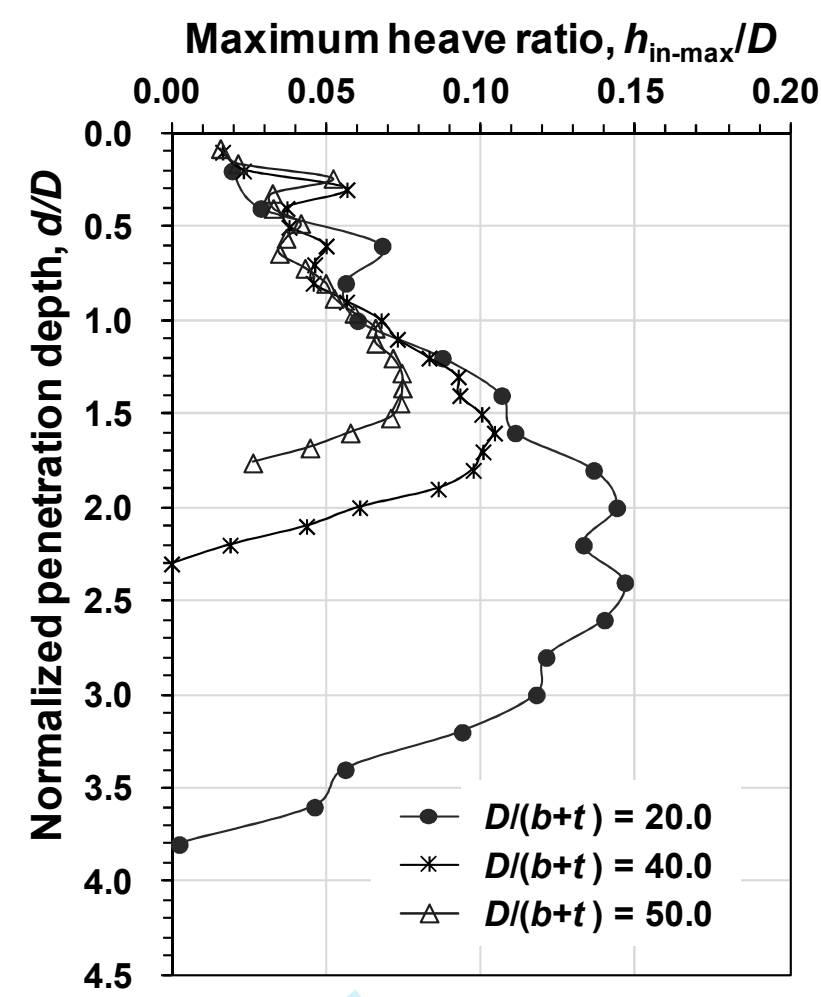

(a) Effect of $D /(b+t)$ on maximum soil heave height: $t=50 \mathrm{~m}, b=150 \mathrm{~mm}$ (varying $D$ )

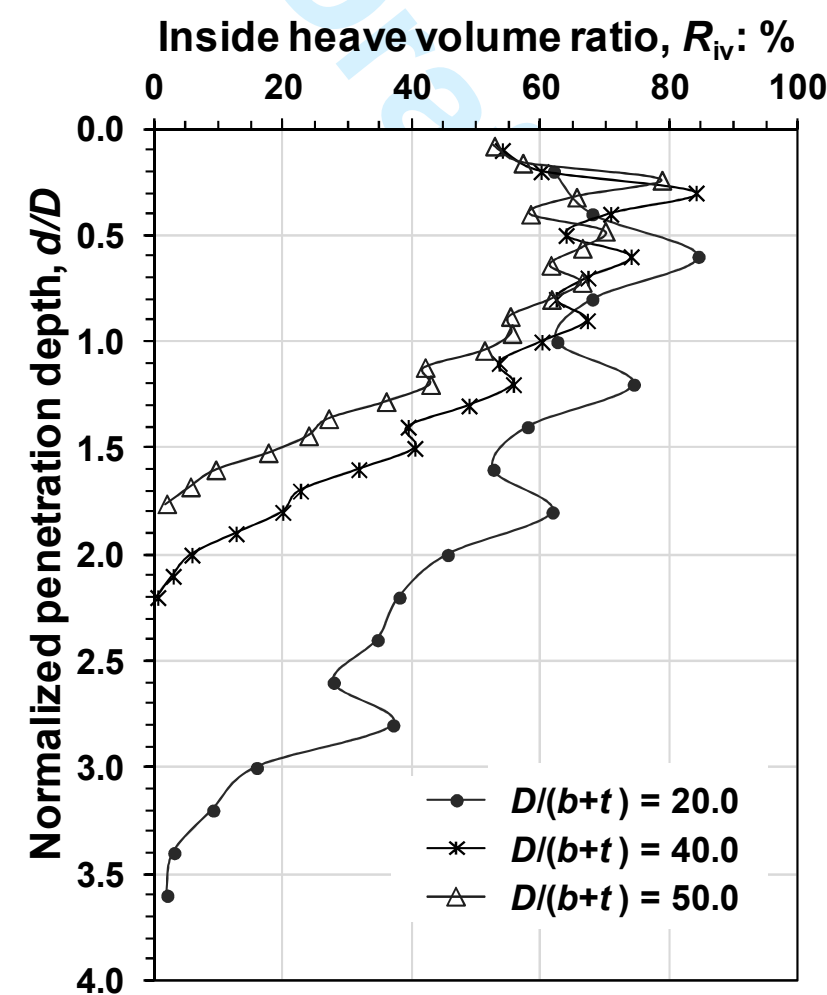

(b) Effect of $D /(b+t)$ on inner heave volume ratio: $t=50 \mathrm{~m}, b=150 \mathrm{~mm}$ (varying $D$ )

Figure 9 Effect of caisson diameter ratio, $D /(b+t)$ (varying $D)$, on inner soil heave $(t=0.05 \mathrm{~m}$, $s_{\mathrm{u}}=1+1 z \mathrm{kPa}$; Group V, Table 2) 


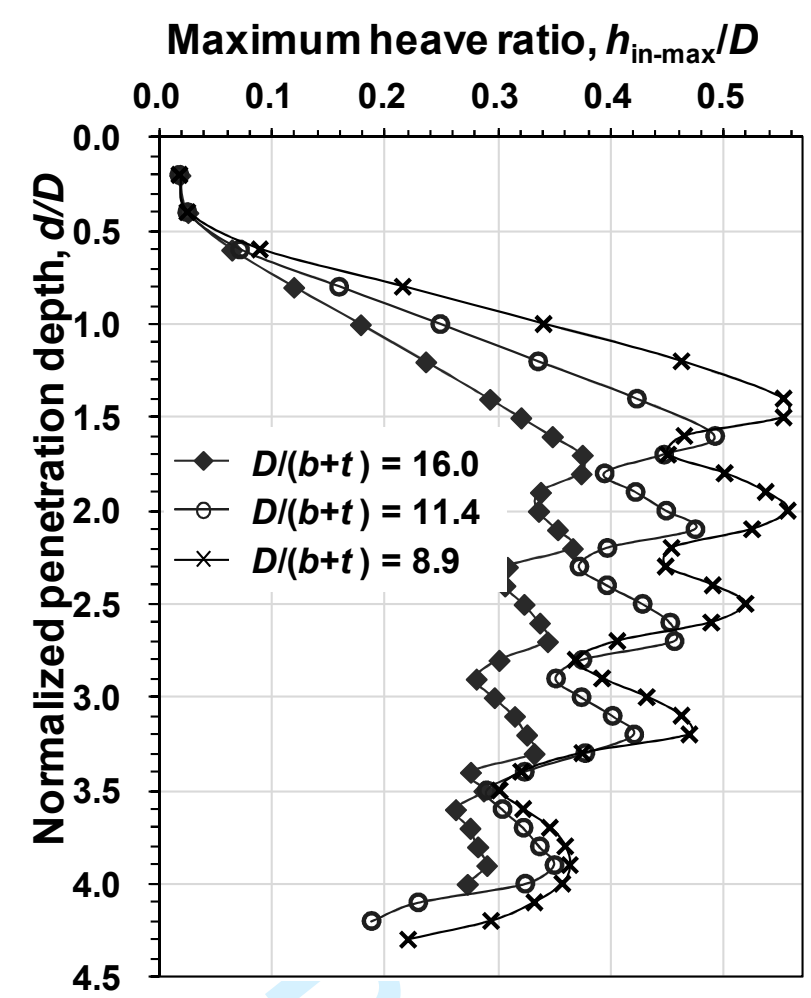

Figure 10 Effect of caisson stiffener width (varying $b$ ) on inner soil heave $\left(t=0.05 \mathrm{~m}, s_{\mathrm{u}}=15\right.$ $+2 z \mathrm{kPa}$; Group VI, Table 2) 


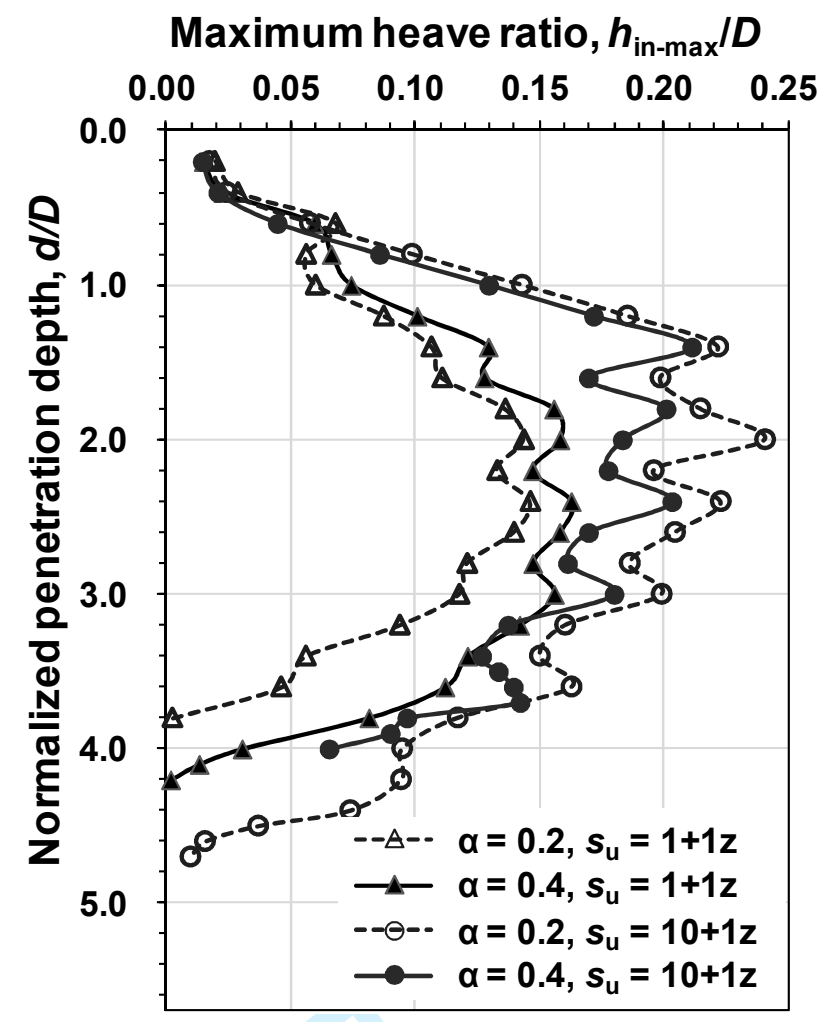

Figure 11 Effect of interface friction coefficient, $\alpha$, on inner maximum heave height $(D=4 \mathrm{~m}$, $t=0.05 \mathrm{~m}$; Group VI, Table 2) 


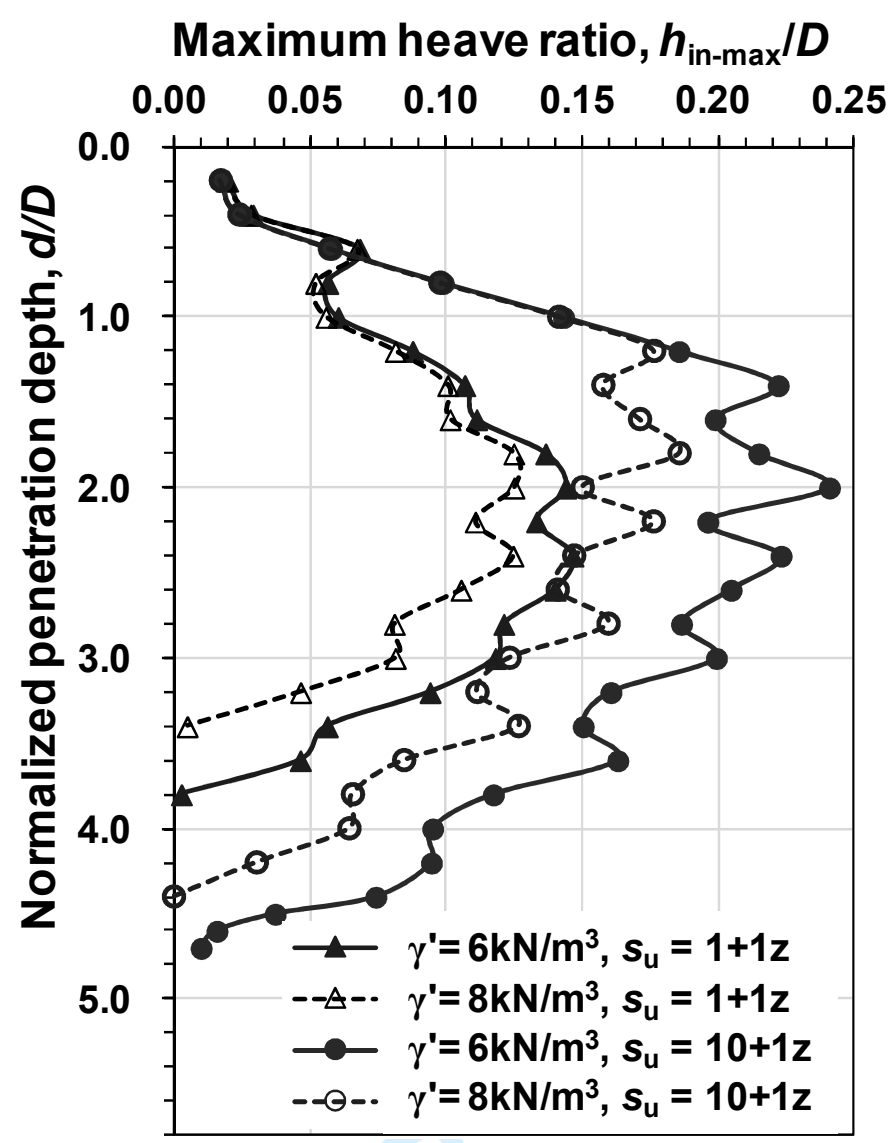

Figure 12 Effect of soil effective unit weight, $\gamma^{\prime}$, on inner maximum heave height $(D=4 \mathrm{~m}, t=$ 0.05 m; Group VII, Table 2) 


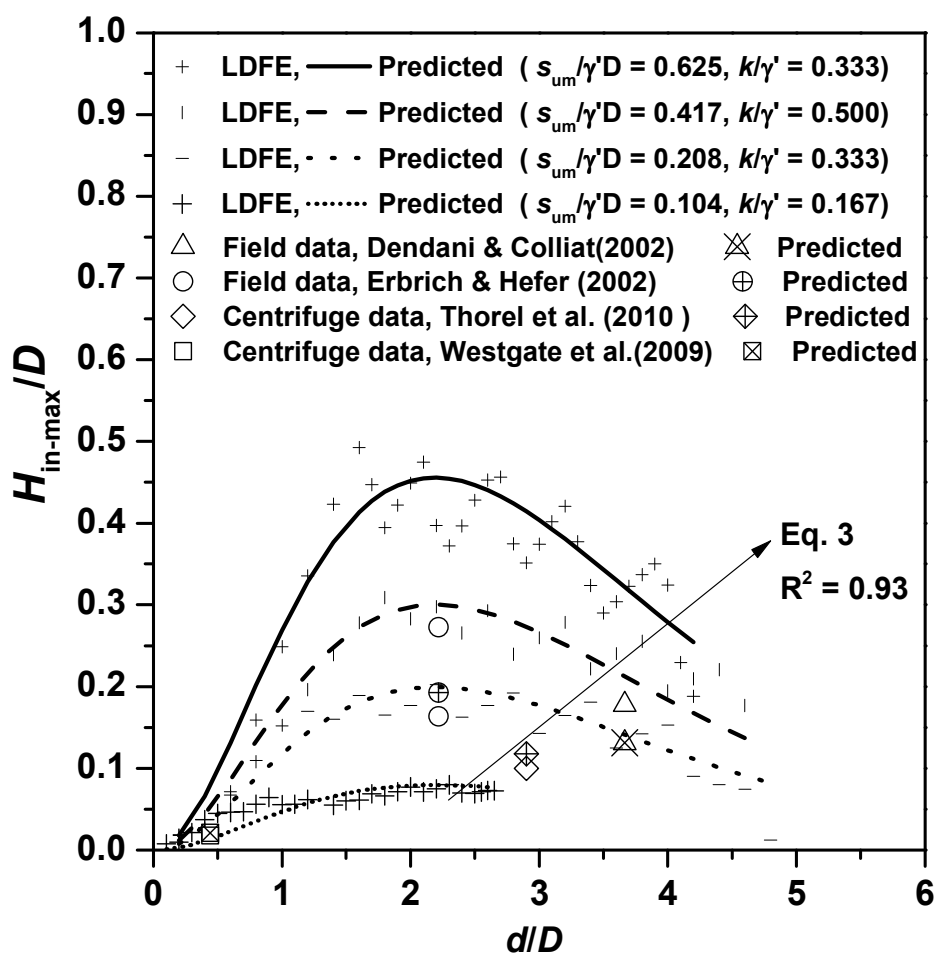

Figure 13 Design chart for inside soil heave 